\title{
Physiological and molecular implications of plant polyamine metabolism during biotic interactions
}

\section{Juan F. Jiménez-Bremont ${ }^{1}$,María Marina ${ }^{2}$, María de la Luz Guerrero-González ${ }^{1}$, Franco R. Rossi ${ }^{2}$, Diana Sánchez-Rangel' , Margarita Rodríguez-Kessler ${ }^{3}$, Oscar A. Ruiz $^{4}$ and Andrés Gárriz ${ }^{2}$ *}

\author{
'División de Biología Molecular, Instituto Potosino de Investigación Científica y Tecnológica, San Luis Potosí, México \\ 2 UB3, Instituto de Investigaciones Biotecnológicas, Instituto Tecnológico de Chascomús, Universidad Nacional de San Martín, Consejo Nacional de \\ Investigaciones Científicas y Técnicas, Chascomús, Argentina \\ ${ }^{3}$ Facultad de Ciencias, Universidad Autónoma de San Luis Potosí, San Luis Potosí, México \\ ${ }^{4}$ UB1, Instituto de Investigaciones Biotecnológicas, Instituto Tecnológico de Chascomús, Universidad Nacional de San Martín, Consejo Nacional de \\ Investigaciones Científicas y Técnicas, Chascomús, Argentina
}

\section{Edited by:}

Ruben Alcazar, Universitat de

Barcelona, Spain

\section{Reviewed by:}

Francisco Marco, Universitat de València, Spain

Panagiotis N. Moschou, Swedish

University of Agricultural Sciences,

Sweden

\section{*Correspondence:}

Andrés Gárriz, UB3, Instituto de Investigaciones Biotecnológicas, Instituto Tecnológico de Chascomús, Universidad Nacional de San Martín, Consejo Nacional de Investigaciones Científicas y Técnicas, Intendente Marino Km 8.2, Chascomús, Buenos Aires 7130, Argentina e-mail:garriz@intech.gov.ar
During ontogeny, plants interact with a wide variety of microorganisms. The association with mutualistic microbes results in benefits for the plant. By contrast, pathogens may cause a remarkable impairment of plant growth and development. Both types of plantmicrobe interactions provoke notable changes in the polyamine (PA) metabolism of the host and/or the microbe, being each interaction a complex and dynamic process. It has been well documented that the levels of free and conjugated PAs undergo profound changes in plant tissues during the interaction with microorganisms. In general, this is correlated with a precise and coordinated regulation of PA biosynthetic and catabolic enzymes. Interestingly, some evidence suggests that the relative importance of these metabolic pathways may depend on the nature of the microorganism, a concept that stems from the fact that these amines mediate the activation of plant defense mechanisms. This effect is mediated mostly through PA oxidation, even though part of the response is activated by non-oxidized PAs. In the last years, a great deal of effort has been devoted to profile plant gene expression following microorganism recognition. In addition, the phenotypes of transgenic and mutant plants in PA metabolism genes have been assessed. In this review, we integrate the current knowledge on this field and analyze the possible roles of these amines during the interaction of plants with microbes.

Keywords: polyamines, spermidine, spermine, putrescine, thermospermine, plant pathogen, mutualism

\section{INTRODUCTION}

The aliphatic polycationic compounds collectively known as polyamines (PAs) have proven to be essential for growth and development in all living organisms (Cohen, 1998). PAs participate in many fundamental processes such as chromatin condensation, DNA replication and transcription, RNA processing, protein synthesis and post-translational modification (Igarashi and Kashiwagi, 2000; Childs et al., 2003; Wallace et al., 2003). The most common PAs in nature are the diamine putrescine (Put), and those traditionally called higher PAs as the triamine spermidine (Spd) and the tetraamines spermine (Spm) and thermospermine (TSpm). In addition, other compounds are also regarded as PAs, such as the diamines 1,3-diaminopropane (DAP) and cadaverine (Cad). Uncommon PAs show a limited distribution in nature and consists of Spd and Spm-related molecules as nor-Spd, nor-Spm, homo-Spd, homo-Spm, and longer pentaand hexaamines (Bagni and Tassoni, 2001; Fuell etal., 2010; Sagor et al., 2013).

In plant tissues, the relative abundance of PAs depends on the species and the developmental stage. They are detected in actively growing plant tissues and in plants exposed to biotic or abiotic stress (Jimenez-Bremont et al., 2007; Rodriguez-Kessler et al., 2008; Alcázar et al., 2010; Gill and Tuteja, 2010; Hussain et al.,
2011). It has been demonstrated that PAs are important for the normal course of diverse plant ontogenic processes such as cell division and elongation, organogenesis and somatic and zygotic embryogenesis (Hummel et al., 2004; Paschalidis and RoubelakisAngelakis, 2005; Mattoo et al., 2010). In general terms, the levels of Put in plants are higher than those of the other PAs (Cohen, 1998). Cad can also be found in considerable high concentrations even though it seems to be limited to legumes and a few species belonging to other plant families (Tomar et al., 2013). Additionally, PAs may exist in soluble as well as insoluble fractions. The soluble fraction consists of free PAs and PAs conjugated to organic acids, mainly hydroxycinnamic acid. In turn, the insoluble fraction is formed by PAs bound to macromolecules such as proteins, cell wall polysaccharides and plasma membrane (Martin-Tanguy, 2001).

Although the exact mechanism of action of PAs remains still elusive, many authors have proposed that the spatial separation of their positive charges under physiological $\mathrm{pH}$ plays a crucial role. This feature gives them the capacity to bind negatively charged molecules such as nucleic acids, phospholipids, and proteins; and it is thought that by these means PAs affect the structure and function of these macromolecules. Moreover, the formation of these compounds protects macromolecules 
from degradation and modification (Ruiz-Herrera et al., 1995; D’Agostino et al., 2005).

There is a considerable amount of information about the role played by PAs during the interactions of plants with either pathogenic or beneficial microbes. These data indicate that changes in PA metabolism constitute a key adaptive response of the plant, and that their occurrence determines the development of the interaction. In turn, evidence suggests that some microorganisms are able to perturb plant PA metabolism in order to adjust it to their own requirements.

In this review, we integrate the current knowledge on the modulation of plant PA metabolism upon pathogen recognition and its importance for plant defense, giving particular emphasis in the advances achieved by the scientific community in the last few years. In addition, we discuss the importance of PAs in beneficial plant interactions, as those established by nitrogen-fixing bacteria and mycorrhizal fungi. The impact of biotechnological approaches and genetic engineered plants with altered PA levels in plant-microbe interactions is also reviewed.

\section{PA METABOLISM IN PLANTS}

The concentration of PAs is finely controlled in eukaryotic cells in order to fulfill the requirements at any time. Precise regulation of PA levels is important since not only its depletion, but also extensive PA accumulation may be deleterious (Ditomaso et al., 1989; He et al., 1993; Poulin et al., 1993). Therefore, several processes such as PA synthesis, catabolism, transport, compartmentalization, and conjugation act in concert to maintain the concentration of these compounds in suitable levels (reviewed by Kusano et al., 2007; Carbonell and Blázquez, 2009). We briefly summarize below the principal aspects of plant PA metabolism.

\section{BIOSYNTHESIS OF PAs}

In plants, the synthesis of Put may be conducted by two pathways (Martin-Tanguy, 2001). One of these metabolic routes starts with the decarboxylation of the amino acid arginine by the enzyme arginine decarboxylase (ADC, EC 4.1.1.19), located mainly in the chloroplast in photosynthetic cells but directed to the nucleus in non-photosynthetic cells (Borrell et al., 1995; Bortolotti et al., 2004). This reaction renders agmatine, which is then metabolized to N-carbamoylputrescine by agmatine iminohydrolase (AIH, EC 3.5.3.12). Consequently, N-carbamoylputrescine is converted in Put by the enzyme N-carbamoylputrescine amidohydrolase (NCPAH, EC 3.5.1.53). The other metabolic pathway begins with the amino acid ornithine converted into Put in a single-step reaction catalyzed by the enzyme ornithine decarboxylase (ODC, EC 4.1.1.17), which is mainly found in the plant cytosol. The synthesis of higher PAs requires decarboxylated S-adenosylmethionine (dcSAM) as aminopropyl donor, generated by the action of the enzyme S-adenosylmethionine decarboxylase (SAMDC, EC 4.1.1.50). dcSAM is then used by the enzyme spermidine synthase (SPDS, EC 2.5.1.16) to add an aminopropyl moiety to Put, hence forming Spd. In a consecutive aminopropylation reaction, the enzyme spermine synthase (SPMS, EC 2.5.1.22) adds an aminopropyl group to Spd converting it to Spm. Alternatively, thermospermine synthase (tSPMS, EC 2.5.1.79) forms TSpm by adding the aminopropyl group to the opposite end of the molecule of Spd.

The relative importance of ADC and ODC activities for Put synthesis varies according to the plant species and the tissue involved (Cohen, 1998; Hanfrey et al., 2001; Flemetakis et al., 2004). In some plant species the ODC gene is absent, as occur in many members of the Brassicaseae family including Arabidopsis thaliana, and in nonvascular plants such as Physcomitrella patens (Jiménez-Bremont et al., 2004; Fuell et al., 2010). In addition, whereas in most plants there is only one gene coding for ADC, two paralogous genes with different patterns of expression occurs in Brassicaseae members (Galloway et al., 1998; Hummel et al., 2001). The disruption of each $A D C$ gene in Arabidopsis does not cause a major phenotypic change, but knocking down both has a lethal effect (Urano et al., 2005).

The Arabidopsis genome contains four genes coding for SAMDCs, two SPDSs, one SPMS and one tSPMS (known as ACAULIS5; Fuell et al., 2010). SPDS and SPMS seem to be localized in the cytoplasm and the nucleus (Belda-Palazón et al., 2012), while SAMDC appears to be mostly cytoplasmic (Torrigiani et al., 1986; Belda-Palazón et al., 2012). Plant SAMDCs are usually regulated at the translational level by PAs (Hanfrey et al., 2002, 2003). It has been shown that a small upstream open reading frame ( $\mathrm{uORF}$ ) in the SAMDC mRNA $5^{\prime}$ leader sequence is responsible for RNA translation repression mediated by PAs. This mechanism regulates the availability of dcSAM for Spd and Spm synthesis, which seems to constitute the main point of regulation for the synthesis of higher PAs in these organisms (Fuell et al., 2010). The double mutants atsamdc2(bud2)-atsamdc1 (Ge et al., 2006) and atspds1-atspds2 (Imai et al., 2004b) are embryo lethal, indicating that higher PAs are essential for plant embryogenesis. This effect could be due to a deficiency in Spd synthesis and not Spm, since no phenotypic effect is evident in spms plants (Imai et al., 2004a). In turn, disruption of the ACAULIS5 gene in Arabidopsis plants lead to a notable dwarf phenotype, demonstrating the importance of TSpm synthesis for plant growth (Imai et al., 2004a).

\section{CATABOLISM OF PAs}

Polyamine catabolism is mediated by diamine oxidases (DAOs, EC 1.4.3.6) and PA oxidases (PAOs, EC 1.5.3.3). DAOs are homodimers with copper as the prosthetic group. These enzymes show a preference for diamines such as Put and Cad, and have low affinity for Spd and Spm. The oxidation of Put renders $\mathrm{H}_{2} \mathrm{O}_{2}$, $\mathrm{NH}_{4}{ }^{+}$and $\gamma$-aminobutanal, the latter being spontaneously converted to $\Delta^{1}$-pyrroline. DAOs from legumes and Arabidopsis have been described to be directed to the extracellular space, remaining in this compartment loosely associated to cell walls (Federico and Angelini, 1991; Moschou et al., 2008b). Recently, it was demonstrated that Arabidopsis has at least ten putative DAO genes, four of which have been characterized: AtCuAO1 and AtAO1 encode for apoplastic proteins, whereas the products of AtCuAO2 and AtCuAO3 are found at the peroxisome (Planas-Portell et al., 2013). Interestingly, $D A O$ genes show different expression profiles in response to external stimuli (Planas-Portell et al., 2013).

Polyamine oxidases use FAD as cofactor and oxidize mainly Spd and Spm. These enzymes may be involved in two different 
catabolic pathways: (1) terminal catabolism and (2) backconversion of PAs. PAOs acting in the terminal catabolism pathway oxidize Spd or Spm using molecular $\mathrm{O}_{2}$ as electron donor. In this case, DAP and $\mathrm{H}_{2} \mathrm{O}_{2}$ are released as final products, besides either 4-aminobutanal or (3-aminopropyl)-4-aminobutanal depending on whether Spd or Spm act as substrate, respectively. Alternatively, enzymes back-converting PAs transform Spm into Spd, and Spd into Put with the concomitant production of 3-aminopropanal and $\mathrm{H}_{2} \mathrm{O}_{2}$. Both types of reactions produce $\mathrm{H}_{2} \mathrm{O}_{2}$ as final product, which plays an essential role in plant-microbe interactions. Five genes coding for PAOs have been identified in Arabidopsis, showing cytosolic (AtPAO1 and AtPAO5) and peroxisomal (AtPAO2, AtPAO3, and AtPAO4) localization (Moschou et al., 2008c; Takahashi et al., 2010; Fincato et al., 2011). It has been demonstrated that AtPAO1 to AtPAO4 catalyze the back conversion of PAs (Tavladoraki et al., 2006; Kamada-Nobusada et al., 2008; Moschou etal., 2008c; Fincato et al., 2011). The peroxisomal back-converting pathway has also been described in rice (Ono etal., 2012), even though all other enzymes characterized in monocotyledonous plants so far are involved in the terminal catabolic pathway (Tavladoraki et al., 1998; Šbela etal., 2001). It was recently found that AtPAO2 in Arabidopsis is negatively modulated in a PA-dependent manner by a uORF located in the $5^{\prime}$-UTR sequence (Guerrero-González et al., 2014). A comparative analysis of several PAO transcripts from different plant species indicated that uORF sequences are very conserved, suggesting a common regulatory mechanism for these enzymes.

\section{TRANSPORT AND CONJUGATION OF PAs}

The transport of PAs into different cell compartments is a crucial step to regulate several cell processes (Igarashi and Kashiwagi, 2010; Mulangi etal., 2012b). Only PA importers have been characterized so far at the functional level in plant cells. The first evidence of PA import was found in carrot protoplasts and isolated vacuoles, and it was suggested that PA entrance is driven by the transmembrane electrical gradient and a possible antiport mechanism (Pistocchi et al., 1988). It was found that external $\mathrm{pH}$ and the concentration of calcium modulate PA uptake (Antognoni et al., 1994; Pistocchi et al., 1988). Recently, the identification and characterization of specific importers has been achieved in rice and Arabidopsis (Fujita et al., 2012; Mulangi et al., 2012a). The first of these proteins reported was OsPUT1 (polyamine uptake transporter) from rice. Radiological uptake and competitive inhibition experiments in a heterologous system revealed that OsPUT1 functions mainly as a Spd importer and that the gene is expressed in all tissues except for mature roots and seeds (Mulangi et al., 2012b). Five additional importers from Arabidopsis and rice were described to form part of the same clade with OsPUT1 and show high affinity for Spd (Mulangi et al., 2012a). A LAT (L-type amino acid transporter) protein in Arabidopsis named RMV1 is involved in the proton-dependent incorporation of PAs with a high affinity for Spm (Fujita et al., 2012). Lastly, PA transport into phloem and xylem tissues has been reported (Friedman et al., 1986), but the cell components involved in this processes have not yet been characterized.
Conjugation of PAs is an additional mechanism used by plant cells to regulate the intracellular concentration of the free forms, and these conjugates may comprehend up to $90 \%$ of the total PA cell content in some plant species (Bagni and Tassoni, 2001). It has been shown in Nicotiana attenuata that different hydroxycinnamoyl transferases (HCTs, EC 2.3.1.138) catalyze the conjugation of caffeoyl, cinammoyl, and feruloyl-CoA to Put or Spd (Onkokesung etal., 2012). It is unknown whether the deconjugation of these compounds is catalyzed by the same transferases. Interestingly, the genes coding for HCTs in N. attenuata are induced by the transcription factor R2R3-NaMYB8, which is known to mediate the defense responses against herbivore attack (Kaur et al., 2010).

\section{PAs AND PLANT-MICROBE INTERACTIONS}

Plant PA metabolism undergoes remarkably changes during plantmicrobe interactions (Walters, 2003; Hussain et al., 2011). The roles played by PAs during these processes are considerably intricate. This is due to the fact that PAs are not only essential to maintain cell viability, but function as signaling molecules regulating many of the responses that help the plant to cope with biotic stress. As will be discussed later, this effect may be exerted either directly by PAs or being mediated through their catabolism. The modulation of PA metabolism is so important for the outcome of the pathogenic interactions that not only the plant modifies PA concentration in response to pathogens, but some microorganisms have developed mechanisms to induce modifications of PA levels in host tissues. Therefore, it seems that when plants are attacked by pathogens, the organism that takes control of the PA machinery has a great opportunity to take the lead. The interaction of plants with beneficial microorganisms also induces changes in PA metabolism, and the establishment of mutualism with symbionts such as Rhizobia and Mycorrhizae appear to depend on PA levels. In the following section we aboard the evidences generated so far regarding the role played by PAs in plant associations with both pathogenic and beneficial microorganisms.

\section{CHANGES IN PLANT PA METABOLISM DURING PATHOGENIC INTERACTIONS}

Research indicates that PAs participate actively during the interactions between plants and pathogens. It has been shown that PAs levels and the activity of PA metabolic enzymes augment in infected tissues during microbial colonization, which seems to be independent of the nature of the pathogen, i.e., biotroph or necrotroph (Walters, 2003; Hussain et al., 2011).

Biotrophic microorganisms feed on nutrients produced by the host living cells (Glazebrook, 2005) and the establishment of this type of interaction leads to the accumulation of PAs in plants. For instance, Greenland and Lewis (1984) reported an increase of Spd in barley (Hordeum vulgare L.) leaves infected with the rust fungus Puccinia hordei, while Spd and Put were increased in this plant species during the infection caused by the powdery mildew fungus Blumeria graminis f. sp. hordei (Walters et al., 1985). Similar effects were demonstrated to occur in the interaction between wheat and Puccinia graminis f. sp. tritici (Machatschke et al., 1990; Foster and Walters, 1992) and in bean plants treated with fungal 
elicitors (Broetto et al., 2005). Importantly, the main increments in PA concentration during the interaction with biotrophs are found in leaf areas close to the pathogen entry point. These areas have been termed "green islands" and are correlated with the induction of photosynthesis and delay in senescence. The accumulation of PAs was explained on the basis of higher activities in plant PA biosynthetic enzymes, in particular that of ADC (Walters and Wylie, 1986; Coghlan and Walters, 1990). Nevertheless, this is not necessarily true for all the interactions involving microorganisms of this kind. For instance, the ODC seems to be responsible for the increment of PAs in wheat leaves infected by Puccinia graminis f. sp. tritici (Foster and Walters, 1992). In this particular case, the authors reported a reduction of ADC activity but a significant induction of ODC activity in the pustules, the sites were fungal spores brake through the plant epidermis. On these grounds, it was hypothesized that the ODC from the pathogen would be responsible for PA production at the infection site.

Variations in PA levels between resistant and susceptible cultivars in response to pathogens has been described. In this trend, the analysis of two genotypes of barley during the interaction with $B$. graminis $\mathrm{f}$. sp. hordei revealed that the resistant cultivar accumulates higher Put and Spd levels than the susceptible one following pathogen infection (Cowley and Walters, 2002a,b; Asthir et al., 2004). Similarly, PAs are accumulated in resistant (but not susceptible) tobacco plants in response to tobacco mosaic virus (TMV; Marini et al., 2001). Accordingly, highly susceptible sugarcane buds infected with the smut fungus Ustilago scitaminea reduce free PA contents while increase their conjugation to phenolic acids (Legaz etal., 1998). The authors attributed the susceptibility of the plant to a reduction in the availability of free phenolic compounds with importance for defense rather than a diminution in free PA concentration. In contrast, Arabidopsis ecotypes Col-0 and Bur-0, which are susceptible and partially resistant to Plasmodiophora brassicae infection, respectively, did not show significant differences in PA contents when challenged with the pathogen. However, susceptible plants displayed a transient accumulation of the PA precursor agmatine and strong arginase activity (the enzyme catalyzing the transformation of arginine in ornithine), whereas partially resistant plants showed continuous agmatine production and weak arginase activity. Based on these observations, it was proposed that symptom development is associated to differences in arginine metabolism and agmatine production (Jubault et al., 2008).

Many studies have shown that any situation leading to free PA accumulation in plants is usually accompanied of a rise in the concentration of conjugated PAs and the induction of PA oxidase activity. This is important because both phenomena could account for the improvement in plant tolerance. Thus, conjugated PAs are accumulated in plant tissues in response to viral and fungal infections (Walters, 2003; Rodriguez-Kessler et al., 2008; Muroi et al., 2009), and it was shown that these compounds affect microbial growth and prevent the development of disease in plants (MartinTanguy et al., 1976; Mackintosh et al., 1997; Walters et al., 2001). Muroi et al. (2009) reported the accumulation of conjugates of agmatine and Put in leaves of $A$. thaliana infected with Alternaria brassicicola. The importance of these compounds in the defense against this pathogen was clearly demonstrated by the interruption of the AtACT gene, encoding an enzyme that conjugates PAs to hydroxycinnamic acid, which enhanced the plant susceptibility. In addition, it has been suggested that PA conjugates contribute to the formation of a phenolic barrier that makes cell walls more resistant to microbial enzymatic hydrolysis (Walters et al., 2001). In turn, PA oxidation could also have a positive effect on plant defense. DAO and PAO activities were induced accompanying the accumulation of free PAs in tobacco and barley plants resistant to TMV and B. graminis f. sp. hordei, respectively (Marini et al., 2001; Cowley and Walters, 2002a,b). Interestingly, plant resistance to pathogens in these cases depends on the activation of the hypersensitive response (HR), which is characterized by host cell death at the infection site. As one of the key steps triggering the HR is the production of $\mathrm{H}_{2} \mathrm{O}_{2}$, it is conceivable that the activity of PA catabolic enzymes contributes to elicit this response. In addition, $\mathrm{H}_{2} \mathrm{O}_{2}$ may promote plant resistance by HR-independent mechanisms, involving cell wall reinforcement, MAPK activation, and modulation of gene expression (Cona et al., 2006a; Nanda et al., 2010). In this regard, PA oxidation was also induced in barley against an incompatible strain of B. graminis, where resistance is not associated to HR induction but depends on the ability to avoid penetration of leaf epidermal cells (Cowley and Walters, 2002a). In the same line of evidences, DAO activity is induced in chickpea in response to the necrotrophic pathogen Ascochyta rabiei, and its inhibition by 2-bromoethylamine reduces plant resistance (Rea et al., 2002). Necrotrophic pathogens kill the host cells to feed on the remaining, and it has been demonstrated that the activation of HR ultimately favors host colonization (Govrin and Levine, 2000). Therefore, it might be expected that the resistance to Ascochyta rabiei mediated by PA oxidation would be due to a mechanism other than HR.

\section{DIRECT MODULATION OF HOST PA METABOLISM BY PHYTOPATHOGENIC MICROBES}

Plant tumor-like structures provoked by pathogens show a remarkably induction of PA synthesis and increase in PA concentration. For instance, PAs accumulate in turnip roots infected by Plasmodiophora brassicae Woron., a microorganism that produce hypertrophy and hyperplasia of infected tissues in members of the plant family Brassicaceae (Walters and Shuttleton, 1985). Similar increments in free and conjugated PAs were described in maize tumors produced by the fungus Ustilago maydis (RodriguezKessler et al., 2008), where ADC and SAMDC activities played a major role. These observations raise an interesting question that has remained elusive so far: are pathogens able to modulate plant PA metabolism in their own favor? Recent studies demonstrate that it might be the case for some interactions. Cytokinins produced by Rhodococcus fascians induce Put accumulation in Arabidopsis by activating ADC expression, which contributes to symptom development (Stes et al., 2011). Moreover, PA synthesis is induced in cabbage protoplasts infected by TYMV and it was demonstrated that these newly synthesized PAs are incorporated by viral particles (Balint and Cohen, 1985). It has not been proven yet if this is triggered by signals generated by this pathogen to assure survival in the host cells. In turn, perhaps 
one of the most direct evidences demonstrating the modulation of plant PA metabolism by a pathogen is the interaction between the protein 10A06 secreted by the nematode Heterodera schachtii and the product of the SPDS2 gene of Arabidopsis. Interestingly, expression of 10A06 in Arabidopsis enhanced plant susceptibility, which was associated to the activation of SPDS2 gene expression, the increment in Spd concentration and the activation of PAO activity (Hewezi et al., 2010). Surprisingly, over-expression of SPDS2 was sufficient to affect plant defense. A further examination of these phenotypes demonstrated that $10 A 06$ or SPDS2 expression increases the abundance of several transcripts coding for host antioxidant enzymes. Based on this, the authors hypothesized that the induction of $\mathrm{PAO}$ activity imposes oxidative stress to plant cells and that this is counteracted by the activation of the antioxidant machinery, which might create a less hostile environment for the pathogen. In this same line, it was demonstrated that the protein $\mathrm{C} 2$ of the beet severe curly top virus (BSCTV) interacts with SAMDC1 in Arabidopsis, which contributes to increment plant susceptibility (Zhang et al., 2011b). In this case, it was found that $\mathrm{C} 2$ interacts with a region of SAMDC1 containing a PEST sequence (enriched in the amino acids Pro, Glu, Ser, and Thr), thereby attenuating its degradation at the proteasome. In this context, the stabilization of SAMDC activity leads to a low SAM/dcSAM ratio, thus reducing host and viral DNA methylation. It is though that this hypomethylated environment facilitates viral replication. Whether direct interaction with host PA metabolism enzymes is a general virulence mechanism for pathogens has not been further evaluated. Interestingly, a recent work by Kim et al. (2013a) demonstrated that the interaction between PA metabolic enzymes and pathogen effectors could also be used by plants to trigger defense. Thus, the effector protein AvrBsT of Xanthomonas campestris pv. vesicatoria is recognized by the ADC1 protein at the cytoplasm of pepper cells, and this interaction enhances AvrBsT-mediated cell death and plant resistance.

\section{TRANSGENIC MODULATION OF PLANT PA LEVELS TO IMPROVE THE TOLERANCE TO PATHOGENS}

Several genetically engineered plant lines with altered PA levels show increased tolerance to microorganism attack. This fact constitutes another line of evidence demonstrating the importance of PAs during plant-pathogen interactions. In relation to this, tobacco plants over-expressing the human SAMDC gene accumulate free and conjugated PAs and show higher tolerance to pathogens (Waie and Rajam, 2003). Similarly, transgenic eggplants over-expressing the oat $A D C$ gene acquired resistance to wilt disease caused by the fungus Fusarium oxysporum (Prabhavathi and Rajam, 2007). These plants showed increased ADC activity and accumulation of PAs, particularly the conjugated forms of Put and Spm. As the DAO activity was also enhanced, it was suggested that the acquisition of resistance might be due to an integrated mechanism involving PA biosynthesis and degradation rather than a single event. In turn, over-expression of human SAMDC gene in tomato conferred resistance to the fungal pathogens F. oxysporum and Alternaria solani (Hazarika and Rajam, 2011), and the over-expression of an apple SPDS gene in sweet orange enhances plant tolerance to Xanthomonas axonopodis pv. citri (Fu etal.,
2011; Fu and Liu, 2013). At last, the over-expression of the SPMS gene in $A$. thaliana resulted in higher Spm levels and enhanced resistance against Pseudomonas viridiflava (Gonzalez et al., 2011). Promoting PA oxidation might also favor plant defense. Regarding this, the over-expression of an extracellular PAO from maize in tobacco plants leads to an increment in the expression of genes related to systemic acquired resistance and cell wall-based defense (Moschou et al., 2009). These changes confer disease resistance against Pseudomonas syringae pv. tabaci and Phytophthora parasitica, but not against infections caused by the cucumber mosaic virus.

\section{PAs AND DEFENSE HORMONE METABOLISM}

Polyamine metabolism is modulated by exogenous application of phytohormones known to be associated to plant defense. However, only a few works addressed the relationship between PAs and defense hormones in a plant-pathogen system. For instance, treatment of barley primary leaves with methyl-jasmonate (MeJA) induces the increment in free and conjugated Put and Spd, as well as in ODC, ADC, SAMDC, and DAO activities (Walters et al., 2002). Conjugated PA accumulation was extended to non-treated leaves and correlated with a reduction in powdery mildew infection in these tissues. It was also shown that application of MeJA entails PA accumulation in loquat fruits and reduction of the symptoms associated to anthracnose rot caused by Colletotrichum acutatum (Cao et al., 2014). Similarly, treatment of wheat with MeJA increases the concentrations of both free and conjugated PAs and induces ODC and PAO activities. The change in PA metabolism was correlated with the induction of pathogenesis related (PR) proteins such as peroxidases and chitinases and a reduction in the incidence of infections by Puccinia recondita (Haggag and Abd-El-Kareem, 2009). The over-accumulation of conjugated PAs and induction of PA oxidation mediated by jasmonates (Jas) was also reported to occur in Hycoscyamus muticus L. root cultures, tobacco leaf disks and chickpea plants (Biondi et al., 2000, 2003; Biondi and Scaramagli, 2001; Rea et al., 2002). The effect of MeJA on conjugated PA levels is exacerbated in tobacco transgenic lines expressing a SAMDC gene in antisense, which showed low SAMDC activity and a relative accumulation of Put (Torrigiani et al., 2005). Interestingly, treatment of Arabidopsis plants with MeJA increases the expression of $A D C 2$ while $A D C 1$ remains unaltered, suggesting the existence of different regulatory pathway for both genes (Perez-Amador et al., 2002). Importantly, ADC2 is regulated by a stress-induced kinase cascade involving MPK3 and MPK6 and is important for defense against P. syringae pv. tomato DC3000 (Kim et al., 2013b). Two ODC genes are also induced in tobacco in response to MeJA, but its importance for plant defense has not been explored (Xu et al., 2004). The effect of MeJA on PA metabolism may be quite different in other plant species. Thus, it has been shown that MeJA caused a transient inhibition at the transcriptional levels of the expression of ADC, SAMDC, and SPDS in rice (Peremarti et al., 2010). These data could be explained by the existence of contrasting regulatory mechanisms operating over the metabolic enzymes in different plant species. In addition, it should also be considered that the expression of PA metabolism genes not only 
depends on the action of one hormone, but it is influenced by several signaling pathways. Thus, it has been demonstrated that the effect of MeJA on ODC and SAMDC activities function synergistically with that of auxins in tobacco leaf disks, but it is counteracted by cytokinins (Biondi etal., 2003). In Arabidopsis, MeJA induces the expression of $\mathrm{CuAO1}, \mathrm{CuAO2}$, and $\mathrm{CuAO3}$, and it was shown that $\mathrm{CuAO}$ and $\mathrm{CuAO} 3$ also respond to abscisic acid (ABA; Wimalasekera et al., 2011b; Planas-Portell et al., 2013).

Salicylic acid (SA) plays a fundamental role in plant defense (Glazebrook, 2005). Unfortunately, the current information concerning the relationship between SA and PAs is scarce. It has been shown that $\mathrm{SA}$ is able to induce the accumulation of PAs by activating the expression of $A D C$ and $O D C$ in maize, tobacco, and tomato (Németh et al., 2002; Jang et al., 2009; Zhang et al., 2011a). Nevertheless, it has not been evaluated yet whether JA and SA act synergistic on the activities of these enzymes. In chickpea plants, however, the application of SA repressed the induction of PA oxidation mediated by JA (Rea et al., 2002). In turn, ABA has been recently demonstrated to induce DAO expression in Arabidopsis (Wimalasekera et al., 2011b). ABA is also able to induce Put oxidation at the apoplast of Vicia faba (An et al., 2008). This was demonstrated to be important for stomatal closure, a known mechanism contributing to prevent plant colonization by bacterial pathogens. Future research is necessary to understand the connections between $\mathrm{SA}$ and $\mathrm{ABA}$ metabolism with PAs during plant biotic stress.

The infection of tomato and purple passion (Gynura aurantiaca) plants with the citrus exocortis viroid (CEVd) induces ethylene production and represses PR expression. This is accompanied by a reduction in ODC activity, which leads to a decline in Put contents (Belles et al., 1991, 1993). Importantly, the reduction in Put concentration is absent with the use of ethylene biosynthesis inhibitors or compounds that prevent the action of the hormone, suggesting that ethylene exerts an inhibitory effect on ODC activity. Conversely, PAs may also interfere with ethylene metabolism. This was demonstrated in a tomato transgenic line expressing the yeast SPDS gene and showing relatively high levels of Spd (Nambeesan et al., 2012). This line exhibits high susceptibility to the attack of the fungus Botrytis cinerea, which seems to be due to an attenuated expression of ethylene biosynthetic and signaling genes.

\section{PAs AS MEDIATORS OF PLANT DEFENSE ACTIVATION}

Increasing evidences demonstrate that PAs and their catabolic products (i.e., $\mathrm{H}_{2} \mathrm{O}_{2}$ ) can act as defense signaling molecules. This function has been mostly assigned to Spm, even though it has been shown that in some systems either Put, Spd, or TSpm participate in defense activation.

During TMV infection, Spm is accumulated in the apoplast of tobacco. This change induces the expression of acidic and basic PRs in a SA-independent pathway and is associated to resistance to virus infection (Yamakawa et al., 1998). Further studies demonstrated that Spm oxidation at the apoplast is crucial to elicit defense responses, and that this pathway involves the activation of key MAPK proteins as SIPK and WIPK (Takahashi etal., 2003; Moschou et al., 2008a). This signaling cascade also requires the opening of the mitochondrial pore and $\mathrm{Ca}^{2+}$ influx in this organelle, suggesting that a disruption of the electrochemical potential at this membrane participates in the process. Gene expression analysis in different plant species showed that Spm mediates the induction of several defense genes, such as members of the hairpin-induced 1 (HIN1) family (Takahashi et al., 2004a), proteinase inhibitors (Raju et al., 2009), the transcription repressor ZFT1 (Mitsuya et al., 2007), and HR-associated factors (Takahashi et al., 2004b). In tobacco, the activation of the Spm pathway ultimately leads to the induction of programmed cell death, thus promoting resistance to TMV. In relation to this, it has been shown that Spm is able to activate NHL10 expression in Arabidopsis, another gene induced during HR (Zheng etal., 2005). The involvement of Spm in defense gene activation may be even broader in this species, where $90 \%$ of the genes regulated by this PA also respond during the HR elicited by an avirulent virus (Sagor et al., 2009). Most of these genes are important for cell redox homeostasis, protein metabolism and plant defense. Recent evidences demonstrated that the response triggered by Spm is not only restricted to HR-related genes. In this regard, Gonzalez et al. (2011) evaluated the transcriptome of an Arabidopsis line overexpressing the SPMS gene, which showed high tolerance to the virulent bacteria $P$. viridiflava by mechanisms that are independent of HR induction. This analysis revealed that Spm accumulation induces the expression of genes involved in pathogen perception and defense, including several regulatory proteins such as transcription factors and kinases. By the use of a PAO inhibitor the authors showed that the induction in gene expression may be mostly explained through Spm oxidation, even though part of the response if carried out by the native non-oxidized PA.

Put and Spd were also described to participate in plant defense in Arabidopsis and tobacco, respectively. In this trend, Put treatment reduces pathogen susceptibility of an $A D C 2$ mutant of Arabidopsis, suggesting that this diamine is involved in defense responses (Kim et al., 2013b). On the other hand, Spd accelerated the induction of HR and improves the tolerance against TMV of tobacco leaf disks (Lazzarato et al., 2009). In addition, tobacco plants treated with Spd showed higher levels of SA and expression of PRs, besides the induction of systemic acquired resistance. Constitutive expression of a SPDS gene in sweet orange also modifies the expression of a large group of genes, many of them with a potential function in plant defense (Fu and Liu, 2013). However, as Put and Spd function as precursors of Spm, it is not clear whether these PAs by their self are able to induce plant defense or rather it is carried out after its conversion to Spm.

In turn, TSpm has received particular attention in the last years. It has been shown that it is equally efficient at inducing defense gene expression as its isomer Spm (Sagor etal., 2012; Marina et al., 2013). In fact, exogenous TSpm is able to restrict CMV multiplication in Arabidopsis (Sagor et al., 2012) and improve the resistance of this species to P. viridiflava (Marina et al., 2013). In agreement with this, the over-expression of ACAULIS5 in Arabidopsis enhances tolerance to bacterial attack while null mutant lines are more susceptible. Importantly, the use of PA oxidase inhibitors impairs resistance in the ACAULIS5 transgenic 
lines, suggesting that TSpm oxidation is crucial to elicit plant resistance (Marina etal., 2013). Other longer uncommon PA isomers (caldopentamine, caldohexamine, and homocaldopentamine) have recently been described to induce defense gene expression in an even stronger way than that of Spm. These molecules are also oxidized in plant tissues but at lower rates than other PAs (Sagor et al., 2013). In addition, they are able to induce the expression of NADPH oxidase genes, the enzyme that produce superoxide anion $\left(\mathrm{O}_{2}^{-}\right)$and thus contribute to ROS accumulation.

Finally, it has been suggested that PA action is mediated through the generation of nitric oxide (NO), a key mediator of plant defense. This is based on studies in Arabidopsis seedlings where it was shown that exogenous Spd and Spm increased NO production (Wimalasekera et al., 2011a). However, the interplay between $\mathrm{PA}$ and $\mathrm{NO}$ metabolism during pathogenic interactions in plants has not been evaluated to the present.

Polyamine oxidation plays an essential role during PA signal transduction. Importantly, the activities of these enzymes are increased upon pathogen contact, particularly in resistant cultivars, and transgenic plants constitutively expressing PA oxidase genes present higher tolerance to pathogen attack (Yoda et al., 2006; Moschou et al., 2008a, 2009). Conversely, the use of oxidase inhibitors or oxidase gene deletion strongly impairs plant resistance (Yoda et al., 2009; Choi and Hwang, 2012). Because PAO and DAO activities result in the production of $\mathrm{H}_{2} \mathrm{O}_{2}$, a process that contributes to elicit host cell death, it has been proven that the importance of PA oxidation depends on the life-style of the pathogen. For instance, oxidation of PAs was demonstrated to be beneficial for plant defense in pathosystems involving biotrophic or hemibiotrophic pathogens (Yoda et al., 2006, 2009; Moschou et al., 2009). By contrast, the induction of host cell death by PA oxidation facilitated pathogen spreading in plants interacting with necrotrophic microorganisms (Marina et al., 2008). The activation of defense responses mediated by these enzymes may not be attributed only to $\mathrm{H}_{2} \mathrm{O}_{2}$ production, since other reaction products may give rise to intermediaries with a substantial role during biotic stress. For instance, $\Delta^{1}$-pirroline derived from Put and Spd oxidation is further metabolized to $\gamma$-aminobutyric acid (GABA), a compound largely associated to plant defense (Bouche and Fromm, 2004). Additionally, DAP could be also converted in $\beta$-alanine and uncommon PAs, all of them proposed to be involved in plant resistance (Cona et al., 2006b).

In particular, PA oxidation might have an important role when occurring at the apoplast. In this trend, Marina etal. (2008) demonstrated that oxidase activities are induced in apoplast of tobacco leaf disks challenged with very dissimilar pathogens such as $P$. viridiflava and Sclerotinia sclerotiorum. By the use of specific inhibitors of PA oxidation, they showed that this is important to avoid colonization by the bacteria, which presents a biotrophic lifestyle, but favors the disease caused by the necrotrophic fungus S. sclerotiorum. Likewise, the extracellular diamine oxidase AtCuAO1 is induced in Arabidopsis by stress-related stimuli as treatment with SA, MeJA, flagellin, and ABA (Planas-Portell et al., 2013). In tobacco, the oxidation of apoplastic PAs induces the HR during TMV infection and this is essential for defense against the bacterium $P$. syringae pv. tabaci and the oomycete Phytophthora parasitica var. nicotianae (Yoda et al., 2003; Moschou et al., 2009). In this trend, the expression of an extracellular PAO from maize in tobacco cells is sufficient to induce programmed cell death when PAs are exogenously added (Rea et al., 2004). Besides the induction of HR, it has been demonstrated that the oxidation of PAs at the apoplast is important to strengthen cell wall during pathogen attack (Cona et al., 2006a; Angelini et al., 2010).

\section{PLANT PA METABOLISM IN THE INTERACTION WITH BENEFICIAL MICROORGANISMS}

Many soil-borne microorganisms have been well studied for their beneficial effects on plant growth and are classified into different categories, as nitrogen-fixing bacteria (rhizobia), mycorrhizal fungi, plant growth promoting rhizobacteria, mycoparasitic fungi, etc (Mendes et al., 2013). The current evidence demonstrating the influence of PA metabolism in the establishment and development of beneficial associations is relatively scarce in comparison with that obtained from studies on pathogenic associations. The research conducted in this area has been mainly focused in two groups: the nitrogen-fixing bacteria and mychorrizal fungi.

\section{PAs AND NODULATION IN LEGUMES}

Symbiotic nitrogen fixation results from the interaction between legume plants and soil-borne bacteria called rhizobia. This interaction leads to the formation of a novel plant organ, the root nodule, in which rhizobia differentiate into specific nitrogen-fixing bacteroids able to reduce atmospheric nitrogen to ammonia (Oldroyd and Downie, 2008). Many studies demonstrate that nodule initiation and development is regulated by the availability of nitrogen. In addition, it has been shown that changes in PA concentration might affect the control of root nodule number and biomass (Vassileva and Ignatov, 1999; Terakado et al., 2006).

It is well known that root nodules accumulate PAs to levels that are 5 to 10 times higher than in non-symbiotic organs, even though the composition of PAs depends on the legume species studied (Fujihara et al., 1994; Efrose et al., 2008). It has been proposed that PA accumulation in mature nitrogen-fixing nodules could be a mechanism to enhance nodule tolerance to the osmotic stress caused by the establishment of the symbiotic interaction. Studies of symbiosis in Lotus japonicus indicate the occurrence of a coordinated spatial and temporal induction of PA biosynthesis genes throughout the nodule life, where the expression of LjSPDS and LjSPMS is particularly high in the earlier stages of nodule development (i.e., 10 days post-infection) and decline thereafter. Interestingly, the expression pattern of these genes did not correlate with Spd and Spm levels, which are incremented in later stages of nodulation (Efrose et al., 2008). This observation may reflect higher Spd and Spm catabolism rates in early stages, in which $\mathrm{H}_{2} \mathrm{O}_{2}$ may promote cross-linking of a plant matrix glycoprotein associated with the lumen of the infection threads, the initial structure that allows rhizobia colonization of root hairs (Wisniewski et al., 2000). DAO deficient plant lines are less efficient in cross-linking the matrix glycoprotein but they does not show a difference in nodule formation when compared to control plants, suggesting that Put oxidation plays a 
minor role in nodule initiation (Wisniewski and Brewin, 2000). These lines though, are less sensitive to the inhibition of nodule formation that Put exerts on wild type plants. These data indicates that products derived from Put oxidation may delay nodule development.

In the nitrogen-fixing interaction between Galega orientalis and Rhizobium galegae, the exogenous application of PAs (mainly Put) at concentrations ranging from 10 to $50 \mu \mathrm{M}$ exerts stimulatory effects in the number and biomass of nodules. In addition, it stimulates nitrogen fixation and enhances the ability of the Rhizobium strain HAMBI 540 to attach to Galega roots (Vassileva and Ignatov, 1999). However, the exposition of this plant species to higher concentrations of PAs $(100 \mu \mathrm{M})$ impairs nodule function and originates specific structural abnormalities, indicating that a fine balance in PA concentration must exist in the plantrhizobia interphase to avoid deleterious effects on nodules and roots.

The relative concentration of each PA appears to be relevant to control nodulation in legumes. In this regard, it has been demonstrated that the soybean supernodulating mutant En6500 maintains high Put levels but low concentrations of Spd and Spm in leaves, roots and nodules in comparison to its parent plant Enrei (Terakado etal., 2006). Importantly, treatment of leaves with an inhibitor of Spd synthesis increases nodule formation in Enrei, whereas Spd and Spm applied to foliar tissues reduce nodulation in both mutant and parental lines. The supernodulating phenotype showed by the mutant line is probably caused by a deficiency in the metabolism of brassinosteroid, a hormone that probably induces Spd synthesis. In fact, exogenous application of the brassinosteriod brassinolide not only reduces root nodule number in this mutant, but also restores Spd levels (Terakado et al., 2006).

Uncommon PAs may also have important functions in nodule development. These PAs have been found in legume root nodules, and in many cases their synthesis and/or accumulation was restricted to these organs (Fujihara, 2009). For example, the tetraamines homo-Spd and the Spm analog canavalmine were identified exclusively in senescent nodules of the sword bean Canavalia gladiata (Fujihara et al., 1986). Unsaturated analogs of Spd, such as $\mathrm{N}$-(3-aminopropyl)-1,4-diamino-2-butene and $\mathrm{N}$-(4-aminobutyl)-1,4-diamino-2-butene, have been identified in root nodules induced by Bradyrhizobium japonicum (Fujihara and Yoneyama, 1999). It is still not clear if these PAs are produced by rhizobia and exported to the plant or whether they are actually produced by the plant cells. In Medicago sativa nodules, it was found that the high content of homo-Spd is provided by the bacteroid (López-Gómez et al., 2014).

Likewise, metabolites derived from PA catabolism appear to be important for nodulation. For instance, it has been proposed that GABA (which may be produced from 4-aminobutanal) has a dual role, acting as signaling molecule during plant-bacteria communication and also functioning as an amino acid precursor in bacterial metabolism (Sulieman, 2011). In this trend, feeding with GABA into the phloem sap of Medicago truncatula plants causes a short-term increase in nodule activity and a remarkably increment in the amino acid and organic acid content in nodules (Sulieman and Schulze, 2010).

\section{PAs AS INDUCTORS OF THE PLANT-MYCORRHIZAL ASSOCIATION}

Plant root symbioses with fungi, referred as mycorrhiza, occur in different forms (Parniske, 2008). In this mutualistic association, the fungi are adapted to live using nutrients provided by the plant, usually nitrogen and carbohydrates. In return, the fungus augments water and minerals availability for the plant. The establishment of this interaction is accompanied by a complex exchange of signaling molecules between the symbiont and the plant, and it has been suggested that PAs may play an important role in this process (Niemi et al., 2002, 2006).

Exogenous application of PAs has a positive effect during the formation of mycorrhizal symbiosis. El Ghachtouli et al. (1995) observed that PAs significantly increased the frequency of mycorrhizal colonization in pea roots. Similarly, application of Put and Spm to trifoliate orange (Poncirus trifoliata) seedlings increased mycorrhizal colonization by Glomus versiforme, whereas Spd did not influence this parameter (Wu and Zou, 2009). This study also showed that PA treatment enhances leaf $\mathrm{Mn}^{2+}$ and root $\mathrm{Ca}^{2+}$ uptake. Therefore, it was concluded that PAs stimulate the colonization of roots by the fungus, hence helping the host to absorb minerals. Moreover, it has been reported that the exogenous application of PAs in combination with mycorrhiza colonization alter the morphology of plant roots (Wu et al., 2012). Thus, Citrus tangerine plants treated with PAs were better colonized by the fungus Paraglomus occultum and showed an increment in root length, diameter, surface area, and volume, as well as higher root branching. Similarly, treatment of Citrus limonia seedlings with either Put or Spd increases root length and augments the mitotic index of root tip cells (Yao et al., 2010). These data indicates that PAs are involved in root elongation of citrus plants. Likewise, the exogenous addition of Put, Spm, and Spm at $1 \mu \mathrm{M}$ improves rooting frequency and provokes root elongation in Virginia pine (Pinus virginiana; Tang and Newton, 2005).

Some evidence demonstrates that mycorrhizae formation can result in changes in both free and conjugated PA levels in plant tissues. Thus, Kytöviita and Sarjala (1997) observed that PA concentration (mainly Put and Spd) augmented in root tips of old pine (Pinus sylvestris) inoculated with Suillus variegatus in comparison with non-mycorrhizal tips. Total free PA pools were also increased in Lotus glaber following colonization by Glomus intraradices, augmenting the Spd/Spm to Put ratio. It has been suggested that this is one of the mechanisms by which mycorrhizal fungi enhance plant adaptation to saline soils (Sannazzaro et al., 2007). Up to now, little is known about the molecular events that precede the changes in the content of PAs during the establishment of mutualistic association with mycorrhiza-forming fungi.

\section{CONCLUDING REMARKS AND FUTURE PERSPECTIVES}

The experimental work conducted so far clearly indicates that PAs exert important biological activities during the establishment of plant-microbe interactions (see Figure 1). In brief, these data indicate that:

(a) Changes in PA levels occur in plants following microbe recognition. PA biosynthesis tends to be induced during this 


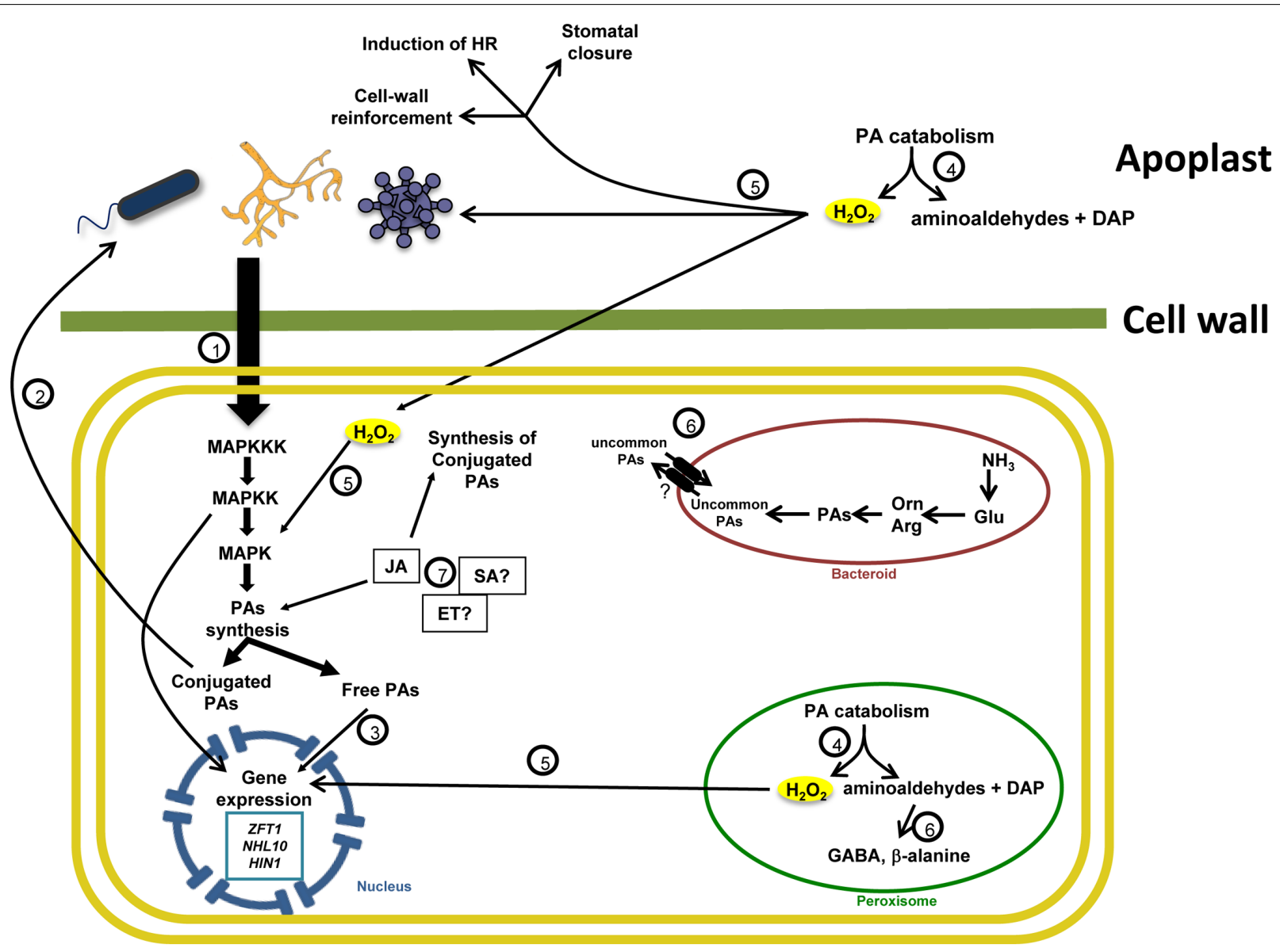

FIGURE 1 | Polyamine metabolism in plant-microorganism interactions. (1) The presence of microorganisms is perceived by specific plant receptors that activate signal transduction pathways. Many MAP kinases, such as WIPK and SIPK, participate in these pathways stimulating defense gene expression and PA biosynthesis. This process leads to the accumulation of free and conjugated PAs. (2) Some conjugated PAs have an antimicrobial effect. (3) In turn, free PAs might contribute to the activation of gene expression directly or through their catabolism. (4) PA oxidation by DAO and PAO occurs in the peroxisome and apoplast, with the generation of $\mathrm{H}_{2} \mathrm{O}_{2}$, DAP and aminoaldehydes. (5) $\mathrm{H}_{2} \mathrm{O}_{2}$ acts as signaling molecule and stimulates defense gene expression. In addition, this molecule affect pathogen growth, induces cell-wall reinforcement and stomatal closure, and activates the HR. Other products from the oxidation of PAs may play a defensive role. For instance, aminoaldehydes are precursors for the biosynthesis of GABA in the cytosol and peroxisome, which participate in plant defense and plant-bacteria communication. DAP is a substrate for the synthesis of uncommon PAs and $\beta$-alanine, compounds that appear to have an important role during plant biotic stress. (6) Phytohormones such as JA contribute to defense responses by stimulating PA biosynthesis and conjugation. The role of SA and Ethylene in PA metabolism is less clear. process, which usually lead to the accumulation of the free and conjugated forms of these compounds. The timeline of accumulation as well as the nature of the PAs accumulated depend on the type of the interaction being established and the species involved in the interaction

(b) The role of PAs during plant-microbe interactions might be the result of multiple mechanisms, i.e., their interaction with macromolecules, regulation of gene expression and protein stability, and the induction of defense signaling pathways.

(c) The accumulation of PAs is often accompanied by the induction of PA oxidation. PA catabolism is essential to trigger plant defense responses particularly when occurring at the apoplast, even though part of this response is also induced by non-oxidized PAs.

(d) The establishment of beneficial and pathogenic interactions might be dependent on PAs. Recent evidences suggest that both plant and microorganisms have evolved mechanisms to modulate PA metabolism in their own advantage.

In spite of the above mentioned, there are still several issues to be addressed in order to have a full understanding of the participation of plant PAs in the outcome of these associations. For instance, little is known about the mechanisms used by cells to transport different PAs to organelles and apoplast, and whether these compounds are actively transported between the plant cells and microbes. Additional research is needed to identify the molecular mechanisms that regulate PA metabolism and the main targets of PAs during the induction of plant defense, including the cross-regulation between PAs and phytohormones. These studies should involve not only the most common PAs referred in this review, but also other non-canonical molecules. At last, it is also essential to know the significance of the mechanisms 
deployed by microbes to perturb host PA metabolism, as well as the effects that PAs produced by these organisms may have on plant physiology.

Current genetic strategies such as the generation of transgenic and mutant plant lines in addition to genome-wide expression analyses of plants either under pathogenic or mutualistic interactions will help to unravel the regulatory networks that control PA metabolism in plants. The expression of genes of PA metabolism in transgenic lines should be driven by promoters specifically induced by microorganisms, since constitutive expression could offer undesirable characteristics. These studies will provide a better knowledge of the roles played by these biological amines in the development of plant-microbe interactions. It is conceivable that a deeper understanding in this field will make wonderful contributions to the design of better strategies to control plant diseases and favor beneficial plant-microbe associations.

\section{ACKNOWLEDGMENTS}

This work was supported by: Consejo Nacional de Investigaciones Científicas y Técnicas (CONICET, Argentina); Agencia Nacional de Promoción Científica y Tecnológica (ANPCYT, Argentina); CONACYT (Investigación Científica Básica 2011-169509)

Franco R. Rossi is a doctoral fellow from CONICET; María Marina, Oscar A. Ruiz and Andrés Gárriz are members of the researcher Career of CONICET. Juan F. Jiménez-Bremont is research professor at IPICYT; Maria de la Luz Guerrero-González is a doctoral fellow from CONACYT; Diana Sánchez-Rangel is a post-doctoral fellow from CONACYT and Margarita RodríguezKessler is research professor at UASLP. We thank Irma Ortíz for revising the English language.

\section{REFERENCES}

Alcázar, R., Altabella, T., Marco, F., Bortolotti, C., Reymond, M., Koncz, C., et al. (2010). Polyamines: molecules with regulatory functions in plant abiotic stress tolerance. Planta 231, 1237-1249. doi: 10.1007/s00425-010-1130-0

An, Z., Jing, W., Liu, Y., and Zhang, W. (2008). Hydrogen peroxide generated by copper amine oxidase is involved in abscisic acid-induced stomatal closure in Vicia faba. J. Exp. Bot. 59, 815-815. doi: 10.1093/jxb/erm370

Angelini, R., Cona, A., Federico, R., Fincato, P., Tavladoraki, P., and Tisi, A. (2010). Plant amine oxidases "on the move": an update. Plant Physiol. Biochem. 48, 560-564. doi: 10.1016/j.plaphy.2010.02.001

Antognoni, F., Casali, P., Pistocchi, R., and Bagni, N. (1994). Kinetics and calciumspecificity of polyamine uptake in carrot protoplasts. Amino Acids 6, 301-309. doi: 10.1007/BF00813750

Asthir, B., Spoor, W., and Duffus, C. (2004). Involvement of polyamines, diamine oxidase and polyamine oxidase in resistance of barley to Blumeria graminis $\mathrm{f} . \mathrm{sp}$. hordei. Euphytica 136, 307-312. doi: 10.1023/B:EUPH.0000032730.48474.b1

Bagni, N., and Tassoni, A. (2001). Biosynthesis, oxidation and conjugation of aliphatic polyamines in higher plants. Amino Acids 20, 301-317. doi: 10.1007/s007260170046

Balint, R., and Cohen, S. S. (1985). The effects of dicyclohexylamine on polyamine biosynthesis and incorporation into turnip yellow mosaic virus in Chinese cabbage protoplasts infected in vitro. Virology 144, 194-203. doi: 10.1016/0042-6822(85)90317-4

Belda-Palazón, B., Ruiz, L., Martí, E., Tárraga, S., Tiburcio, A. F., Culiáñez, F., et al. (2012). Aminopropyltransferases involved in polyamine biosynthesis localize preferentially in the nucleus of plant cells. PLOS ONE 7:e46907. doi: 10.1371/journal.pone.0046907

Belles, J. M., Carbonell, J., and Conejero, V. (1991). Polyamines in plants infected by citrus exocortis viroid or treated with silver ions and ethephon. Plant Physiol. 96, 1053-1059. doi: 10.1104/pp.96.4.1053
Belles, J. M., Perez-Amador, M. A., Carbonell, J., and Conejero, V. (1993). Correlation between ornithine decarboxylase and putrescine in tomato plants infected by citrus exocortis viroid or treated with ethephon. Plant Physiol. 102, 933-937. doi: 10.1104/pp.102.3.933

Biondi, S., Fornalé, S., Oksman-Caldentey, K. M., Eeva, M., Agostani, S., and Bagni, N. (2000). Jasmonates induce over-accumulation of methylputrescine and conjugated polyamines in Hyoscyamus muticus L. root cultures. Plant Cell Rep. 19, 691-697. doi: 10.1007/s002999900178

Biondi, S., and Scaramagli, S. (2001). Methyl jasmonate upregulates biosynthetic gene expression, oxidation and conjugation of polyamines, and inhibits shoot formation in tobacco thin layers. J. Exp. Bot. 52, 231-242. doi: 10.1093/jexbot/52.355.231

Biondi, S., Scoccianti, V., Scaramagli, S., Ziosi, V., and Torrigiani, P. (2003). Auxin and cytokinin modify methyl jasmonate effects on polyamine metabolism and ethylene biosynthesis in tobacco leaf discs. Plant Sci. 165, 95-101. doi: 10.1016/s0168-9452(03)00147-x

Borrell, A., Culianez-Macia, F. A., Altabella, T., Besford, R. T., Flores, D., and Tiburcio, A. F. (1995). Arginine decarboxylase is localized in chloroplasts. Plant Physiol. 109, 771-776.

Bortolotti, C., Cordeiro, A., Alcázar, R., Borrell, A., Culiañez-Macià, F. A., Tiburcio, A. F., et al. (2004). Localization of arginine decarboxylase in tobacco plants. Physiol. Plant. 120, 84-92. doi: 10.1111/j.0031-9317.2004.0216.x

Bouche, N., and Fromm, H. (2004). GABA in plants: just a metabolite? Trends Plant Sci. 9, 110-115. doi: 10.1016/j.tplants.2004.01.006

Broetto, F., Marchese, J. A., Leonardo, M., and Regina, M. (2005). Fungal elicitormediated changes in polyamine content, phenylalanine-ammonia lyase and peroxidase activities in bean cell culture. Gen. Appl. Plant Physiol. 31, 235-246.

Cao, S., Cai, Y., Yang, Z., Joyce, D. C., and Zheng, Y. (2014). Effect of MeJA treatment on polyamine, energy status and anthracnose rot of loquat fruit. Food Chem. 145, 86-89. doi: 10.1016/j.foodchem.2013.08.019

Carbonell, J., and Blázquez, M. A. (2009). Regulatory mechanisms of polyamine biosynthesis in plants. Genes Genomics 31, 107-118. doi: 10.1007/BF03191144

Childs, A. C., Mehta, D. J., and Gerner, E. W. (2003). Polyamine-dependent gene expression. Cell Mol. Life Sci. 60, 1394-1406. doi: 10.1007/s00018-003-2332-4

Choi, H. W., and Hwang, B. K. (2012). The pepper extracellular peroxidase CaPO2 is required for salt, drought and oxidative stress tolerance as well as resistance to fungal pathogens. Planta 235, 1369-1382. doi: 10.1007/s00425-011-1580-z

Coghlan, S. E., and Walters, D. R. (1990). Polyamine metabolism in "green-islands" on powdery mildew-infected barley leaves: possible interactions with senescence. New Phytol. 116, 417-424. doi: 10.1111/j.1469-8137.1990.tb00527.x

Cohen, S. (1998). A Guide to the Polyamines. New York: Oxford University Press.

Cona, A., Rea, G., Angelini, R., Federico, R., and Tavladoraki, P. (2006a). Functions of amine oxidases in plant development and defence. Trends Plant Sci. 11, 80-88. doi: 10.1016/j.tplants.2005.12.009

Cona, A., Rea, G., Botta, M., Corelli, F., Federico, R., Angelini, R., et al. (2006b). Flavin-containing polyamine oxidase is a hydrogen peroxide source in the oxidative response to the protein phosphatase inhibitor cantharidin in Zea mays L. J. Exp. Bot. 57, 2277-2289. doi: 10.1093/jxb/erj195

Cowley, T., and Walters, D. R. (2002a). Polyamine metabolism in an incompatible interaction between barley and the powdery mildew fungus, Blumeria graminis f. sp. hordei. J. Phytopathol. 150, 581-586. doi: 10.1046/j.1439-0434.2002. 00816.x

Cowley, T., and Walters, D. R. (2002b). Polyamine metabolism in barley reacting hypersensitively to the powdery mildew fungus Blumeria graminis $\mathrm{f}$. $\mathrm{sp}$. hordei. Plant Cell Environ. 25, 461-468. doi: 10.1046/j.0016-8025.2001.00819.x

D’Agostino, L., Di Pietro, M., and Di Luccia, A. (2005). Nuclear aggregates of polyamines are supramolecular structures that play a crucial role in genomic DNA protection and conformation. FEBS J. 272, 3777-3787. doi: 10.1111/j.17424658.2005.04782.x

Ditomaso, J. M., Shaff, J. E., and Kochian, L. V. (1989). Putrescine-induced wounding and its effects on membrane integrity and ion transport processes in roots of intact corn seedlings. Plant Physiol. 90, 988-995. doi: 10.1104/pp.90.3.988

Efrose, R. C., Flemetakis, E., Sfichi, L., Stedel, C., Kouri, E. D., Udvardi, M. K., et al. (2008). Characterization of spermidine and spermine synthases in Lotus japonicus: induction and spatial organization of polyamine biosynthesis in nitrogen fixing nodules. Planta 228, 37-49. doi: 10.1007/s00425-008-07171

El Ghachtouli, N., Paynot, M., Morandi, D., Martin-Tanguy, J., and Gianinazzi, S. (1995). The effect of polyamines on endomycorrhizal infection of wild-type 
Pisum sativum, cv. Frisson (nod $\left.{ }^{+} \mathrm{myc}^{+}\right)$and two mutants $\left(\operatorname{nod}^{-} \mathrm{myc}^{+}\right.$and nod $^{-}$myc $^{-}$). Mycorrhiza 5, 189-192. doi: 10.1007/bf00203336

Federico, R., and Angelini, R. (1991). "Polyamine catabolism in plants," in Biochemistry and Physiology of Polyamines in Plants, eds R. D. Slocum and H. E. Flores (Boca Raton, FL: CRC Press), 41-56.

Fincato, P., Moschou, P. N., Spedaletti, V., Tavazza, R., Angelini, R., Federico, R., et al. (2011). Functional diversity inside the Arabidopsis polyamine oxidase gene family. J. Exp. Bot. 62, 1155-1168. doi: 10.1093/jxb/erq341

Flemetakis, E., Efrose, R. C., Desbrosses, G., Dimou, M., Delis, C., Aivalakis, G., et al. (2004). Induction and spatial organization of polyamine biosynthesis during nodule development in Lotus japonicus. Mol. Plant Microbe Interact. 17, 12831293. doi: 10.1094/mpmi.2004.17.12.1283

Foster, S. A., and Walters, D. R. (1992). Polyamine concentrations and activities of ornithine and arginine decarboxylase in wheat infected with the stem rust fungus. J. Plant Physiol. 140, 134-136. doi: 10.1016/S0176-1617(11)80922-3

Friedman, R., Levin, N., and Altman, A. (1986). Presence and identification of polyamines in xylem and Phloem exudates of plants. Plant Physiol. 82, 1154-1157. doi: $10.1104 / p p .82 .4 .1154$

Fu, X. Z., Chen, C. W., Wang, Y., Liu, J. H., and Moriguchi, T. (2011). Ectopic expression of MdSPDS1 in sweet orange (Citrus sinensis Osbeck) reduces canker susceptibility: involvement of $\mathrm{H}(2) \mathrm{O}(2)$ production and transcriptional alteration. BMC Plant Biol. 11:55. doi: 10.1186/1471-2229-1155

Fu, X.-Z., and Liu, J.-H. (2013). Transcriptional profiling of canker-resistant transgenic sweet orange (Citrus sinensis Osbeck ) constitutively overexpressing a spermidine synthase. Biomed. Res. Int. 2013. doi: 10.1155/2013/918136

Fuell, C., Elliott, K. A., Hanfrey, C. C., Franceschetti, M., and Michael, A. J. (2010). Polyamine biosynthetic diversity in plants and algae. Plant Physiol. Biochem. 48, 513-520. doi: 10.1016/j.plaphy.2010.02.008

Fujihara, S. (2009). Biogenic amines in rhizobia and legume root nodules. Microbes Environ. 24, 1-13. doi: 10.1264/jsme2.ME08557

Fujihara, S., Abe, H., Minakawa, Y., Akao, S., and Yoneyama, T. (1994). Polyamines in nodules from various plant-microbe symbiotic associations. Plant Cell Physiol. $35,1127-1134$

Fujihara, S., Nakashima, T., Kurogochi, Y., and Yamaguchi, M. (1986). Distribution and metabolism of sym-homospermidine and canavalmine in the sword bean Canavalia gladiata cv shironata. Plant Physiol. 82, 795-800. doi: 10.1104/pp.82.3.795

Fujihara, S., and Yoneyama, T. (1999). "Polyamine metabolism of root nodule bacteria," in Recent Research Development in Microbiology, ed. S. G. Pandalai (India: Research Singpost), 55-80.

Fujita, M., Fujita, Y., Iuchi, S., Yamada, K., Kobayashi, Y., Urano, K., et al. (2012). Natural variation in a polyamine transporter determines paraquat tolerance in Arabidopsis. Proc. Natl. Acad. Sci. U.S.A. 109, 6343-6347. doi: 10.1073/pnas.1121406109

Galloway, G. L., Malmberg, R. L., and Price, R. A. (1998). Phylogenetic utility of the nuclear gene arginine decarboxylase: an example from Brassicaceae. Mol. Biol. Evol. 15, 1312-1320. doi: 10.1093/oxfordjournals.molbev.a025859

Ge, C., Cui, X., Wang, Y., Hu, Y., Fu, Z., Zhang, D., et al. (2006). BUD2, encoding an S-adenosylmethionine decarboxylase, is required for Arabidopsis growth and development. Cell Res. 16, 446-456. doi: 10.1038/sj.cr.7310056

Gill, S. S., and Tuteja, N. (2010). Polyamines and abiotic stress tolerance in plants. Plant Signal. Behav. 5, 26-33. doi: 10.4161/psb.5.1.10291

Glazebrook, J. (2005). Contrasting mechanisms of defense against biotrophic and necrotrophic pathogens. Annu. Rev. Phytopathol. 43, 205-227. doi 10.1146/annurev.phyto.43.040204.135923

Gonzalez, M. E., Marco, F., Minguet, E. G., Carrasco-Sorli, P., Blázquez, M. A., Carbonell, J., et al. (2011). Perturbation of spermine synthase gene expression and transcript profiling provide new insights on the role of the tetraamine spermine in Arabidopsis defense against Pseudomonas viridiflava. Plant Physiol. 156, 22662277. doi: 10.1104/pp.110.171413

Govrin, E. M., and Levine, A. (2000). The hypersensitive response facilitates plant infection by the necrotrophic pathogen Botrytis cinerea. Curr. Biol. 10, 751-757. doi: 10.1016/S0960-9822(00)00560-1

Greenland, A. J., and Lewis, D. H. (1984). Amines in barley leaves infected by brown rust and their possible relevance to formation of "green islands". New phytol. 96, 283-291. doi: 10.1111/j.1469-8137.1984.tb03565.x

Guerrero-González, M. L., Rodriguez-Kessler, M., and Jimenez-Bremont, J. F. (2014). uORF, a regulatory mechanism of the Arabidopsis polyamine oxidase 2. Mol. Biol. Rep. doi: 10.1007/s11033-014-3098-5 [Epub ahead of print].
Haggag, W. M., and Abd-El-Kareem, F. (2009). Methyl jasmonate stimulates polyamines biosynthesisand resistance against leaf rust in wheat plants. Arch. Phytopathol. Plant Protect. 42, 16-31. doi: 10.1080/03235400600914355

Hanfrey, C., Franceschetti, M., Mayer, M. J., Illingworth, C., Elliott, K., Collier, M., et al. (2003). Translational regulation of the plant S-adenosylmethionine decarboxylase. Biochem. Soc. Trans. 31, 424-427. doi: 10.1042/BST0310424

Hanfrey, C., Franceschetti, M., Mayer, M. J., Illingworth, C., and Michael, A. J. (2002). Abrogation of upstream open reading frame-mediated translational control of a plant S-adenosylmethionine decarboxylase results in polyamine disruption and growth perturbations. J. Biol. Chem. 277, 44131-44139. doi: 10.1074/jbc.M206161200

Hanfrey, C., Sommer, S., Mayer, M. J., Burtin, D., and Michael, A. J. (2001). Arabidopsis polyamine biosynthesis: absence of ornithine decarboxylase and the mechanism of arginine decarboxylase activity. Plant J. 27, 551-560. doi: 10.1046/j.1365-313X.2001.01100.x

Hazarika, P., and Rajam, M. V. (2011). Biotic and abiotic stress tolerance in transgenic tomatoes by constitutive expression of S-adenosylmethionine decarboxylase gene. Physiol. Mol. Biol. Plants 17, 115-128. doi: 10.1007/s12298-011-0053-y

He, Y., Kashiwagi, K., Fukuchi, J., Terao, K., Shirahata, A., and Igarashi, K. (1993). Correlation between the inhibition of cell growth by accumulated polyamines and the decrease of magnesium and ATP. Eur. J. Biochem. 217, 89-96. doi: 10.1111/j.1432-1033.1993.tb18222.x

Hewezi, T., Howe, P. J., Maier, T. R., Hussey, R. S., Mitchum, M. G., Davis, E. L., et al. (2010). Arabidopsis spermidine synthase is targeted by an effector protein of the cyst nematode Heterodera schachtii. Plant Physiol. 152, 968-984. doi: 10.1104/pp.109.150557

Hummel, I., Bourdais, G., Gouesbet, G., Couée, I., Malmberg, R. L., and Amrani, A. E. (2001). Differential gene expression of ARGININE DECARBOXYLASE ADC1 and ADC2 in Arabidopsis thaliana: characterization of transcriptional regulation during seed germination and seedling development. New Phytol. 519-531. doi: 10.1111/j.1469-8137.2004.01128.x

Hummel, I., Gouesbet, G., El Amrani, A., Aïnouche, A., and Couée, I. (2004). Characterization of the two arginine decarboxylase (polyamine biosynthesis) paralogues of the endemic subantarctic cruciferous species Pringlea antiscorbutica and analysis of their differential expression during development and response to environmental stress. Gene 342, 199-209. doi: 10.1016/j.gene.2004.08.024

Hussain, S. S., Ali, M., Ahmad, M., and Siddique, K. H. M. (2011). Polyamines: natural and engineered abiotic and biotic stress tolerance in plants. Biotechnol. Adv. 29, 300-311. doi: 10.1016/j.biotechadv.2011.01.003

Igarashi, K., and Kashiwagi, K. (2000). Polyamines: mysterious modulators of cellular functions. Biochem. Biophys. Res. Commun. 271, 559-564. doi: 10.1006/bbrc.2000.2601

Igarashi, K., and Kashiwagi, K. (2010). Characteristics of cellular polyamine transport in prokaryotes and eukaryotes. Plant Physiol. Biochem. 48, 506-512. doi: 10.1016/j.plaphy.2010.01.017

Imai, A., Akiyama, T., Kato, T., Sato, S., Tabata, S., Yamamoto, K. T., et al. (2004a). Spermine is not essential for survival of Arabidopsis. DNA Res. 556, 148-152. doi: 10.1016/s0014-5793(03)01395-4

Imai, A., Matsuyama, T., Hanzawa, Y., Akiyama, T., Tamaoki, M., Saji, H., et al. (2004b). Spermidine synthase genes are essential for survival of Arabidopsis. Plant Physiol. 135, 1565-1573. doi: 10.1104/pp.104.041699

Jang, E.-K., Min, K.-H., Kim, S.-H., Nam, S.-H., Zhang, S., Kim, Y. C., et al. (2009). Mitogen-activated protein kinase cascade in the signaling for polyamine biosynthesis in tobacco. Plant Cell Physiol. 50, 658-664. doi: 10.1093/pcp/pcp009

Jiménez-Bremont, J. F., Camacho-Villasana, Y. M., Cabrera-Ponce, J. L., De La Rosa, A. P. B., and Ochoa-Alejo, N. (2004). Sequence comparison of plant ornithine decarboxylases reveals high homology and lack of introns. Biol. Plant. 48, 193198. doi: 10.1023/B:BIOP.0000033444.17603.f2

Jimenez-Bremont, J. F., Ruiz, O. A., and Rodriguez-Kessler, M. (2007). Modulation of spermidine and spermine levels in maize seedlings subjected to long-term salt stress. Plant Physiol. Biochem. 45, 812-821. doi: 10.1016/j.plaphy.2007. 08.001

Jubault, M., Hamon, C., Gravot, A., Lariagon, C., Delourme, R., Bouchereau, A., et al. (2008). Differential regulation of root arginine catabolism and polyamine metabolism in clubroot-susceptible and partially resistant Arabidopsis genotypes. Plant Physiol. 146, 2008-2019. doi: 10.1104/pp.108.117432

Kamada-Nobusada, T., Hayashi, M., Fukazawa, M., Sakakibara, H., and Nishimura, M. (2008). A putative peroxisomal polyamine oxidase, AtPAO4, is involved in 
polyamine catabolism in Arabidopsis thaliana. Plant Cell Physiol. 49, 1272-1282. doi: $10.1093 / \mathrm{pcp} / \mathrm{pcn} 114$

Kaur, H., Heinzel, N., Schottner, M., Baldwin, I. T., and Galis, I. (2010). R2R3NaMYB8 regulates the accumulation of phenylpropanoid-polyamine conjugates, which are essential for local and systemic defense against insect herbivores in Nicotiana attenuata. Plant Physiol. 152, 1731-1747. doi: 10.1104/pp.109.151738

Kim, N. H. D., Kim, B. S. D., and Hwang, B. K. D. (2013a). Pepper arginine decarboxylase is required for polyamine and gamma-aminobutyric acid signaling in cell death and defense response. Plant Physiol. 162, 2067-2083. doi: 10.1104/pp.113.217372

Kim, S. H., Yoo, S. J., Min, K. H., Nam, S. H., Cho, B. H., and Yang, K. Y. (2013b). Putrescine regulating by stress-responsive MAPK cascade contributes to bacteria pathogen defense in Arabidopsis. Biochem. Biophys. Res. Commun. 437, 502-508. doi: 10.1016/j.bbrc.2013.06.080

Kusano, T., Yamaguchi, K., Berberich, T., and Takahashi, Y. (2007). Advances in polyamine research in 2007. J. Plant Res. 120, 345-350. doi: 10.1007/s10265-0070074-3

Kytöviita, M.-M., and Sarjala, T. (1997). Effects of defoliation and symbiosis on polyamine levels in pine and birch. Mycorrhiza 7, 107-111. doi $10.1007 / \mathrm{s} 005720050170$

Lazzarato, L., Trebbi, G., Pagnucco, C., Franchin, C., Torrigiani, P., and Betti, L. (2009). Exogenous spermidine, arsenic and -aminobutyric acid modulate tobacco resistance to tobacco mosaic virus, and affect local and systemic glucosylsalicylic acid. J. Plant Physiol. 166, 90-100. doi: 10.1016/j.jplph.2008. 01.011

Legaz, M. E., Armas, R. D., Piñon, D., and Vicente, C. (1998). Relationships between phenolics-conjugated polyamines and sensitivity of sugarcane to smut (Ustilago scitaminea). J. Exp. Bot. 49, 1723-1728. doi: 10.1093/jxb/49.327.1723

López-Gómez, M., Hidalgo-Castellanos, J., Iribarne, C., and Lluch, C. (2014). Proline accumulation has prevalence over polyamines in nodules of Medicago sativa in symbiosis with Sinorhizobium meliloti during the initial response to salinity. Plant Soil 374, 149-159. doi: 10.1007/s11104-013-1871-1

Machatschke, S., Kamrowski, C., Moerschbacher, B. M., and Reisener, H.-J. (1990). Polyamine levels in stem rust infected wheat leaves and effects of alphadifluoromethylornithine on fungal infection. Physiol. Mol. Plant Pathol. 36 451-459. doi: 10.1016/0885-5765(90)90018-S

Mackintosh, C. A., Slater, L. A., Mcclintock, C. A., Walters, D. R., Havis, N D., and Robins, D. J. (1997). Synthesis and antifungal activity of two novel spermidine analogues. FEMS Microbiol. Lett. 148, 21-25. doi: 10.1111/j.15746968.1997.tb10261.x

Marina, M., Maiale, S. J., Rossi, F. R., Romero, M. F., Rivas, M. E., Gárriz, A., et al. (2008). Apoplastic polyamine oxidation oxidation plays different roles in local responses of tobacco to infection by the necrotrophic fungus Sclerotinia sclerotiorum and the biotrophic bacterium Pseudomonas. Plant Physiol. 147, 2164 2178. doi: 10.1104/pp.108.122614

Marina, M., Sirera, F. V., Rambla, J. L., Gonzalez, M. E., Blázquez, M. A., Carbonell, J., et al. (2013). Thermospermine catabolism increases Arabidopsis thaliana resistance to Pseudomonas viridiflava. J. Exp. Bot. 64, 1393-1402. doi: 10.1093/jxb/ert012

Marini, F., Betti, L., Scaramagli, S., Biondi, S., and Torrigiani, P. (2001). Polyamine metabolism is upregulated in response to tobacco mosaic virus in hypersensitive, but not in susceptible tobacco. New Phytol. 149, 301-309. doi: 10.2307/3186182

Martin-Tanguy, J. (2001). Metabolism and function of polyamines in plants: recent development (new approaches). Plant Growth Regul. 34, 135-148. doi: 10.1023/A:1013343106574

Martin-Tanguy, J., Martin, C., Gallet, M., and Vernoy, R. (1976). Potent natural inhibitors of tobacco mosaic virus multiplication. C. R. Acad. Sci. Hebd. Seances Acad. Sci. D 282, 2231-2234.

Mattoo, A. K., Minocha, S. C., Minocha, R., and Handa, A. K. (2010). Polyamines and cellular metabolism in plants: transgenic approaches reveal different responses to diamine putrescine versus higher polyamines spermidine and spermine. Amino Acids 38, 405-413. doi: 10.1007/s00726-009-0399-4

Mendes, R., Garbeva, P., and Raaijmakers, J. M. (2013). The rhizosphere microbiome: significance of plant beneficial, plant pathogenic, and human pathogenic microorganisms. FEMS Microbiol. Rev. 37, 634-663. doi: 10.1111/15746976.12028

Mitsuya, Y., Takahashi, Y., Uehara, Y., Berberich, T., Miyazaki, A., Takahashi, H., et al. (2007). Identification of a novel Cys 2/His 2 -type zinc-finger protein as a component of a spermine-signaling pathway in tobacco. J. Plant Physiol. 164, 785-793. doi: 10.1016/j.jplph.2006.05.011

Moschou, P. N., Paschalidis, K. A., Delis, I. D., Andriopoulou, A. H., Lagiotis, G. D., Yakoumakis, D. I., et al. (2008a). Spermidine exodus and oxidation in the apoplast induced by abiotic stress is responsible for $\mathrm{H} 2 \mathrm{O} 2$ signatures that direct tolerance responses in tobacco. Plant Cell 20, 1708-1724. doi: 10.1105/tpc.108.059733

Moschou, P. N., Paschalidis, K. A., and Roubelakis-Angelakis, K. A. (2008b). Plant polyamine catabolism: the state of the art. Plant Signal. Behav. 3, 1061-1066. doi: 10.4161/psb.3.12.7172

Moschou, P. N., Sanmartin, M., Andriopoulou, A. H., Rojo, E., Sanchez-Serrano, J. J., and Roubelakis-Angelakis, K. A. (2008c). Bridging the gap between plant and mammalian polyamine catabolism: a novel peroxisomal polyamine oxidase responsible for a full back-conversion pathway in Arabidopsis. Plant Physiol. 147, 1845-1857. doi: 10.1104/pp.108.123802

Moschou, P. N., Sarris, P. F., Skandalis, N., Andriopoulou, A. H., Paschalidis, K. A., Panopoulos, N. J., et al. (2009). Engineered polyamine catabolism preinduces tolerance of tobacco to bacteria and oomycetes. Plant Physiol. 149, 1970-1981. doi: 10.1104/pp.108.134932

Mulangi, V., Chibucos, M. C., Phuntumart, V., and Morris, P. F. (2012a). Kinetic and phylogenetic analysis of plant polyamine uptake transporters. Planta 236, 1261-1273. doi: 10.1007/s00425-012-1668-0

Mulangi, V., Phuntumart, V., Aouida, M., Ramotar, D., and Morris, P. (2012b). Functional analysis of OsPUT1, a rice polyamine uptake transporter. Planta 235, 1-11. doi: 10.1007/s00425-011-1486-9

Muroi, A., Ishihara, A., Tanaka, C., Ishizuka, A., Takabayashi, J., Miyoshi, H., and Nishioka, T. (2009). Accumulation of hydroxycinnamic acid amides induced by pathogen infection and identification of agmatine coumaroyltransferase in Arabidopsis thaliana. Planta 230, 517-527. doi: 10.1007/s00425-009-0960-960.

Nambeesan, S., Abuqamar, S., Laluk, K., Mattoo, A. K., Mickelbart, M. V., Ferruzzi, M. G., et al. (2012). Polyamines attenuate ethylene-mediated defense responses to abrogate resistance to Botrytis cinerea in tomato. Plant Physiol. 158, 1034-1045. doi: 10.1104/pp.111.188698

Nanda, A. K., Andrio, E., Marino, D., Pauly, N., and Dunand, C. (2010). Reactive oxygen species during plant-microorganism early interactions. J. Integr. Plant Biol. 52, 195-204. doi: 10.1111/j.1744-7909.2010.00933.x

Németh, M., Janda, T., Horváth, E., Páldi, E., and Szalai, G. (2002). Exogenous salicylic acid increases polyamine content but may decrease drought tolerance in maize. Plant Sci. 162, 569-574. doi: 10.1016/S0168-9452(01)00593-3

Niemi, K., Haggman, H., and Sarjala, T. (2002). Effects of exogenous diamines on the interaction between ectomycorrhizal fungi and adventitious root formation in Scots pine in vitro. Tree Physiol. 22, 373-381. doi: 10.1093/treephys/22. 6.373

Niemi, K., Sutela, S., Häggman, H., Scagel, C., Vuosku, J., Jokela, A., et al. (2006). Changes in polyamine content and localization of Pinus sylvestris ADC and Suillus variegatus ODC mRNA transcripts during the formation of mycorrhizal interaction in an in vitro cultivation system. J. Exp. Bot. 57, 2795-2804. doi: 10.1093/jxb/erl049.

Oldroyd, G. E., and Downie, J. A. (2008). Coordinating nodule morphogenesis with rhizobial infection in legumes. Annu. Rev. Plant Biol. 59, 519-546. doi: 10.1146/annurev.arplant.59.032607.092839

Onkokesung, N., Gaquerel, E., Kotkar, H., Kaur, H., Baldwin, I. T., and Galis, I. (2012). MYB8 controls inducible phenolamide levels by activating three novel hydroxycinnamoyl-coenzyme A: polyamine transferases in Nicotiana attenuata. Plant Physiol. 158, 389-407. doi: 10.1104/pp.111.187229

Ono, Y., Kim, D. W., Watanabe, K., Sasaki, A., Niitsu, M., Berberich, T., et al. (2012). Constitutively and highly expressed Oryza sativa polyamine oxidases localize in peroxisomes and catalyze polyamine back conversion. Amino Acids 42, 867-876. doi: 10.1007/s00726-011-1002-3

Parniske, M. (2008). Arbuscular mycorrhiza: the mother of plant root endosymbioses. Nat. Rev. Microbiol. 6, 763-775. doi: 10.1038/nrmicro1987

Paschalidis, K. A., and Roubelakis-Angelakis, K. A. (2005). Spatial and temporal distribution of polyamine levels and polyamine anabolism in different organs/tissues of the tobacco plant. Correlations with age, cell division/expansion, and differentiation. Plant Physiol. 138, 142-152. doi: 10.1104/pp.104.055483

Peremarti, A., Bassie, L., Yuan, D., Pelacho, A., Christou, P., and Capell, T. (2010). Transcriptional regulation of the rice arginine decarboxylase (Adc1) and S-denosylmethionine decarboxylase (Samdc) genes by methyl jasmonate. Plant Physiol. Biochem. 48, 553-559. doi: 10.1016/j.plaphy.2010.01.014 
Perez-Amador, M. A., Leon, J., Green, P. J., and Carbonell, J. (2002). Induction of the arginine decarboxylase ADC2 gene provides evidence for the involvement of polyamines in the wound response in Arabidopsis. Plant Physiol. 130, 1454-1463. doi: 10.1104/pp.009951.mechanism

Pistocchi, R., Keller, F., Bagni, N., and Matile, P. (1988). Transport and subcellular localization of polyamines in carrot protoplasts and vacuoles. Plant Physiol. 87 , 514-518. doi: 10.1104/pp.87.2.514

Planas-Portell, J., Gallart, M., Tiburcio, A. F., and Altabella, T. (2013). Coppercontaining amine oxidases contribute to terminal polyamine oxidation in peroxisomes and apoplast of Arabidopsis thaliana. BMC Plant Biol. 13:109. doi: 10.1186/1471-2229-13-109

Poulin, R., Coward, J. K., Lakanen, J. R., and Pegg, A. E. (1993). Enhancement of the spermidine uptake system and lethal effects of spermidine overaccumulation in ornithine decarboxylase-overproducing L1210 cells under hyposmotic stress. J. Biol. Chem. 268, 4690-4698.

Prabhavathi, V. R., and Rajam, M. V. (2007). Polyamine accumulation in transgenic eggplant enhances tolerance to multiple abiotic stresses and fungal resistance. Plant Biotechnol. J. 24, 273-282. doi: 10.5511/plantbiotechnology.24.273

Raju, S., Jayalakshmi, S. K., and Sreeramulu, K. (2009). Differential elicitation of proteases and protease inhibitors in two different genotypes of chickpea (Cicer arietinum) by salicylic acid and spermine. J. Plant Physiol. 166, 1015-1022. doi: 10.1016/j.jplph.2008.12.005

Rea, G., Metoui, O., Infantino, A., Federico, R., and Angelini, R. (2002). Copper amine oxidase expression in defense responses to wounding and Ascochyta rabiei invasion. Plant Physiol. 128, 865-875. doi: 10.1104/pp.010646

Rea, G., Pinto, M. C. D., Tavazza, R., and Biondi, S. (2004). Ectopic expression of maize polyamine oxidase and pea copper amine oxidase in the cell wall of tobacco plants. Plant 134, 1414-1426. doi: 10.1104/pp.103.036764.of

Rodriguez-Kessler, M., Ruiz, O. A., Maiale, S., Ruiz-Herrera, J., and JimenezBremont, J. F. (2008). Polyamine metabolism in maize tumors induced by Ustilago maydis. Plant Physiol. Biochem. 46, 805-814. doi: 10.1016/j.plaphy.2008.05.012

Ruiz-Herrera, J., Ruiz-Medrano, R., and Dominguez, A. (1995). Selective inhibition of cytosine-DNA methylases by polyamines. FEBS Lett. 357, 192-196. doi: 10.1016/0014-5793(94)01360-D

Sagor, G. H. M., Cong, R.-Z., Berberich, T., Takahashi, H., Takahashi, Y., and Kusano, T. (2009). Spermine signaling in defense reaction against avirulent viral pathogen in Arabidopsis thaliana. Plant Signal. Behav. 4, 316-318. doi 10.1016/j.jplph.2008.08.006.Polyamines

Sagor, G. H. M., Liu, T., Takahashi, H., Niitsu, M., Berberich, T., and Kusano, T. (2013). Longer uncommon polyamines have a stronger defense gene-induction activity and a higher suppressing activity of Cucumber mosaic virus multiplication compared to that of spermine in Arabidopsis thaliana. Plant Cell Rep. 32, 1477-1488. doi: 10.1007/s00299-013-1459-5

Sagor, G. H. M., Takahashi, H., Niitsu, M., Takahashi, Y., Berberich, T., and Kusano, T. (2012). Exogenous thermospermine has an activity to induce a subset of the defense genes and restrict cucumber mosaic virus multiplication in Arabidopsis thaliana. Plant Cell Rep. 31, 1227-1232. doi: 10.1007/s00299-012-1243-y

Sannazzaro, A. I., Echeverria, M., Alberto, E. O., Ruiz, O. A., and Menendez, A. B. (2007). Modulation of polyamine balance in Lotus glaber by salinity and arbuscular mycorrhiza. Plant Physiol. Biochem. 45, 39-46. doi: 10.1016/j.plaphy.2006.12.008

Šebela, M., Radová, A., and Angelini, R. (2001). FAD-containing polyamine oxidases: a timely challenge for researchers in biochemistry and physiology of plants. Plant Sci. 160, 197-207. doi: 10.1016/S0168-9452(00)00380-0

Stes, E., Biondi, S., Holsters, M., and Vereecke, D. (2011). Bacterial and plant signal integration via D3-type cyclins enhances symptom development in the Arabidopsis-Rhodococcus fascians interaction. Plant Physiol. 156, 712-725. doi: $10.1104 /$ pp.110.171561

Sulieman, S. (2011). Does GABA increase the efficiency of symbiotic N2 fixation in legumes? Plant Signal. Behav. 6, 32-36.

Sulieman, S., and Schulze, J. (2010). Phloem-derived gamma-aminobutyric acid (GABA) is involved in upregulating nodule N2 fixation efficiency in the model legume Medicago truncatula. Plant Cell Environ. 33, 2162-2172. doi: 10.1111/j.1365-3040.2010.02214.x

Takahashi, Y., Berberich, T., Miyazaki, A., Seo, S., Ohashi, Y., and Kusano, T. (2003). Spermine signalling in tobacco: activation of mitogen-activated protein kinases by spermine is mediated through mitochondrial dysfunction. Plant J. 36, 820-829. doi: 10.1046/j.1365-313X.2003.01923.x
Takahashi, Y., Berberich, T., Yamashita, K., and Uehara, Y. (2004a). Identification of tobacco HIN1 and two closely related genes as spermine-responsive genes and their differential expression during the Tobacco mosaic virus-induced hypersensitive response and during leaf- and flower-senescence. Plant Mol. Biol. 54, 613-622. doi: 10.1023/B:PLAN.0000038276.95539.39

Takahashi, Y., Uehara, Y., Berberich, T., Ito, A., Saitoh, H., Miyazaki, A., et al. (2004b). A subset of hypersensitive response marker genes, including HSR203J, is the downstream target of a spermine signal transduction pathway in tobacco. Plant J. 40, 586-595. doi: 10.1111/j.1365-313X.2004.02234.x

Takahashi, Y., Cong, R., Sagor, G. H. M., Niitsu, M., Berberich, T., and Kusano, T. (2010). Characterization of five polyamine oxidase isoforms in Arabidopsis thaliana. Plant Cell Rep. 29, 955-965. doi: 10.1007/s00299-0100881-1

Tang, W., and Newton, R. J. (2005). Polyamines promote root elongation and growth by increasing root cell division in regenerated Virginia pine (Pinus virginiana Mill) plantlets. Plant Cell Rep. 24, 581-589. doi: 10.1007/s00299-0050021-5

Tavladoraki, P., Rossi, M. N., Saccuti, G., Perez-Amador, M. A., Polticelli, F., Angelini, R., et al. (2006). Heterologous expression and biochemical characterization of a polyamine oxidase from Arabidopsis involved in polyamine back conversion. Plant Physiol. 141, 1519-1532. doi: 10.1104/pp.106.080911.caldohexamine

Tavladoraki, P., Schinina, M. E., Cecconi, F., Di Agostino, S., Manera, F., Rea, G., et al. (1998). Maize polyamine oxidase: primary structure from protein and cDNA sequencing. FEBS Lett. 426, 62-66. doi: 10.1016/S0014-5793(98)00311-1

Terakado, J., Yoneyama, T., and Fujihara, S. (2006). Shoot-applied polyamines suppress nodule formation in soybean (Glycine max). J. Plant Physiol. 163, 497505. doi: 10.1016/j.jplph.2005.05.007

Tomar, P. C., Lakra, N., and Mishra, S. (2013). Cadaverine: a lysine catabolite involved in plant growth and development. Plant Signal. Behav. 8. doi: $10.4161 /$ psb. 25850

Torrigiani, P., Scaramagli, S., Ziosi, V., Mayer, M., and Biondi, S. (2005). Expression of an antisense Datura stramonium S-adenosylmethionine decarboxylase cDNA in tobacco: changes in enzyme activity, putrescine-spermidine ratio, rhizogenic potential, and response to methyl jasmonate. J. Plant Physiol. 162, 559-571. doi: 10.1016/j.jplph.2004.10.008

Torrigiani, P., Serafini-Fracassini, D., Biondi, S., and Bagni, N. (1986). Evidence for the subcellular localization of polyamines and their biosynthetic enzymes in plant cells. J. Plant Physiol. 124, 23-29. doi: 10.1016/S0176-1617(86)80174-2

Urano, K., Hobo, T., and Shinozaki, K. (2005). Arabidopsis ADC genes involved in polyamine biosynthesis are essential for seed development. FEBS Lett. 579, 1557-1564. doi: 10.1016/j.febslet.2005.01.048

Vassileva, V., and Ignatov, G. (1999). Polyamine-induced changes in symbiotic parameters of the Galega orientalis-Rhizobium galegae nitrogen-fixing system. Plant Soil 210, 83-91. doi: 10.1023/a:1004636800869

Waie, B., and Rajam, M. V. (2003). Effect of increased polyamine biosynthesis on stress responses in transgenic tobacco by introduction of human S-adenosylmethionine gene. Plant Sci. 164, 727-734. doi: 10.1016/s01689452(03)00030-x

Wallace, H. M., Fraser, A. V., and Hughes, A. (2003). A perspective of polyamine metabolism. Biochem. J. 376, 1-14. doi: 10.1042/BJ20031327

Walters, D. R. (2003). Polyamines and plant disease. Phytochemistry 64, 97-107. doi: 10.1016/S0031-9422(03)00329-7

Walters, D., Cowley, T., and Mitchell, A. (2002). Methyl jasmonate alters polyamine metabolism and induces systemic protection against powdery mildew infection in barley seedlings. J. Exp. Bot. 53, 747-756. doi: 10.1093/jexbot/53.369.747

Walters, D., Meurer-Grimes, B., and Rovira, I. (2001). Antifungal activity of three spermidine conjugates. FEMS Microbiol. Lett. 201, 255-258. doi: 10.1111/j.15746968.2001.tb10765.x

Walters, D. R., and Shuttleton, M. A. (1985). Polyamines in the roots of turnip infected with Plasmodiophora brassicae Wor. New Phytol. 100, 209-214. doi: 10.1111/j.1469-8137.1985.tb02772.x

Walters, D. R., Wilson, P. W. F., and Shuttleton, M. A. (1985). Changes in levels of polyamines and activities of their biosynthetic enzymes in barley infected with the powdery mildew fungus, Erysiphe graminis DC ex Merat f. sp. New Phytol. 101, 695-705. doi: 10.1111/j.1469-8137.1985.tb02875.x

Walters, D. R., and Wylie, M. A. (1986). Polyamines in discrete regions of barley leaves infected with the powdery mildew fungus, Erysiphe graminis. Physiol. Plant. 67, 630-633. doi: 10.1111/j.1399-3054.1986.tb05068.x 
Wimalasekera, R., Tebartz, F., and Scherer, G. F. E. (2011a). Polyamines, polyamine oxidases and nitric oxide in development, abiotic and biotic stresses. Plant Sci. 181, 593-603. doi: 10.1016/j.plantsci.2011.04.002

Wimalasekera, R., Villar, C., Begum, T., and Scherer, G. F. E. (2011b). COPPER AMINE OXIDASE1 (CuAO1) of Arabidopsis thaliana contributes to abscisic acid- and polyamine-induced nitric oxide biosynthesis and abscisic acid signal transduction. Mol. Plant 4, 663-678. doi: 10.1093/mp/ssr023

Wisniewski, J. P., and Brewin, N. J. (2000). Construction of transgenic pea lines with modified expression of diamine oxidase and modified nodulation responses with exogenous putrescine. Mol. Plant Microbe Interact. 13, 922-928. doi: 10.1094/MPMI.2000.13.9.922

Wisniewski, J. P., Rathbun, E. A., Knox, J. P., and Brewin, N. J. (2000). Involvement of diamine oxidase and peroxidase in insolubilization of the extracellular matrix: implications for pea nodule initiation by Rhizobium leguminosarum. Mol. Plant Microbe Interact. 13, 413-420. doi: 10.1094/MPMI.2000.13.4.413

Wu, Q.-S., and Zou, Y.-N. (2009). The effect of dual application of arbuscular mycorrhizal fungi and polyamines upon growth and nutrient uptake on trifoliate orange (Poncirus trifoliata) seedlings. Not. Bot. Horti. Agrobot. Cluj Napoca 37.

Wu, Q.-S., Zou, Y.-N., Liu, C.-Y., and Lu, T. (2012). Interacted effect of abuscular mycorrhizal fungi and polyamines on root system architecture of Citrus seedlings. J. Integr. Agric. 11, 1675-1681. doi: 10.1016/S2095-3119(12)60170-1

Xu, B., Sheehan, M., and Timko, M. (2004). Differential induction of ornithine decarboxylase (ODC) gene family members in transgenic tobacco (Nicotiana tabacum L. cv. Bright Yellow 2) cell suspensions by methyl-jasmonate treatment. Plant Growth Regul. 44, 101-116. doi: 10.1023/B:GROW.0000049419. 22779.f5

Yamakawa, H., Kamada, H., Satoh, M., and Ohashi, Y. (1998). Spermine is a salicylate-independent endogenous inducer for both tobacco acidic pathogenesisrelated proteins and resistance against tobacco mosaic virus. Plant Physiol. 118, 1213-1222. doi: 10.1104/pp.118.4.1213

Yao, Q., Wang, L.-R., Xing, Q.-X., Chen, J.-Z., and Zhu, H.-H. (2010). Exogenous polyamines influence root morphogenesis and arbuscular mycorrhiza development of Citrus limonia seedlings. Plant Growth Regul. 60, 27-33. doi: 10.1007/s10725-009-9415-7

Yoda, H., Fujimura, K., Takahashi, H., Munemura, I., Uchimiya, H., and Sano, H. (2009). Polyamines as a common source of hydrogen peroxide in host- and nonhost hypersensitive response during pathogen infection. Plant Mol. Biol. 70, 103-112. doi: 10.1007/s11103-009-9459-0
Yoda, H., Hiroi, Y., and Sano, H. (2006). Polyamine oxidase is one of the key elements for oxidative burst to induce programmed cell death in tobacco cultured cells. Plant Physiol. 142, 193-206. doi: 10.1104/pp.106.080515

Yoda, H., Yamaguchi, Y., and Sano, H. (2003). Induction of hypersensitive cell death by hydrogen peroxide produced through polyamine degradation in tobacco plants. Plant Physiol. 132, 1973-1981. doi: 10.1104/pp.103.024737.Polyamines

Zhang, X., Shen, L., Li, F., Meng, D., and Sheng, J. (2011a). Methyl salicylateinduced arginine catabolism is associated with up-regulation of polyamine and nitric oxide levels and improves chilling tolerance in cherry tomato fruit. J. Agr. Food Chem. 59, 9351-9357. doi: 10.1021/jf201812r

Zhang, Z., Chen, H., Huang, X., Xia, R., Zhao, Q., Lai, J., et al. (2011b). BSCTV C2 attenuates the degradation of SAMDC1 to suppress DNA methylation-mediated gene silencing in Arabidopsis. Plant Cell 23, 273-288. doi: 10.1105/tpc.110.081695 Zheng, M. S., Takahashi, H., Miyazaki, A., Yamaguchi, K., and Kusano, T. (2005). Identification of the cis-acting elements in Arabidopsis thaliana NHL10 promoter responsible for leaf senescence, the hypersensitive response against Cucumber mosaic virus infection, and spermine treatment. Plant Sci. 168, 415-422. doi: 10.1016/j.plantsci.2004.09.016

Conflict of Interest Statement: The authors declare that the research was conducted in the absence of any commercial or financial relationships that could be construed as a potential conflict of interest.

Received: 19 January 2014; paper pending published: 27 January 2014; accepted: 25 February 2014; published online: 18 March 2014.

Citation: Jiménez-Bremont JF, Marina M, Guerrero-González ML, Rossi FR, SánchezRangel D, Rodríguez-Kessler M, Ruiz OA and Gárriz A (2014) Physiological and molecular implications of plant polyamine metabolism during biotic interactions. Front. Plant Sci. 5:95. doi: 10.3389/fpls.2014.00095

This article was submitted to Plant Metabolism and Chemodiversity, a section of the journal Frontiers in Plant Science.

Copyright (C) 2014 Jiménez-Bremont, Marina, Guerrero-González, Rossi, SánchezRangel, Rodríguez-Kessler, Ruiz and Gárriz. This is an open-access article distributed under the terms of the Creative Commons Attribution License (CC BY). The use, distribution or reproduction in other forums is permitted, provided the original author(s) or licensor are credited and that the original publication in this journal is cited, in accordance with accepted academic practice. No use, distribution or reproduction is permitted which does not comply with these terms. 